\title{
JAAS
}

\section{Sensitive High Resolution Ion MicroProbe - Stable Isotope \\ (SHRIMP-SI) analysis of water in silicate glasses and nominally anhydrous reference minerals}

\begin{tabular}{|r|l|}
\hline Journal: & Journal of Analytical Atomic Spectrometry \\
\hline Manuscript ID: & JA-ART-02-2015-000047.R1 \\
\hline Article Type: & Paper \\
\hline Date Submitted by the Author: & $15-$ Apr-2015 \\
\hline Complete List of Authors: & $\begin{array}{l}\text { Turner, Michael; Macquarie University, Earth and Planetary Sciences } \\
\text { Ireland, Trevor; Australian National University, Research School of Earth } \\
\text { Sciences } \\
\text { Hermann, Joerg; Australian National University, Research School of Earth } \\
\text { Sciences } \\
\text { Padron-Navarta, Jose Alberto; University of Montpellier and CNRS, } \\
\text { Geoscience Montpellier } \\
\text { Hauri, Erik; Carnegie Institution of Washington, Department of Terrestrial } \\
\text { Magnetism } \\
\text { Holden, Peter; Australian National University, Research School of Earth } \\
\text { Sciences } \\
\text { Turner, Simon; Macquarie University, Earth and Planetary Sciences }\end{array}$ \\
\hline
\end{tabular}

\section{SCHOLARONE ${ }^{\text {Tw }}$}


1 Sensitive High Resolution Ion MicroProbe - Stable Isotope

2 (SHRIMP-SI) analysis of water in silicate glasses and

3 nominally anhydrous reference minerals

4

5

Low-level water measurements of geological materials are fundamental in understanding the volatile inventories of the Earth from the mantle to crustal reservoirs. Here we describe the development of microanalytical techniques using the new SHRIMP SI ion microprobe to measure the abundances of $\mathrm{OH}^{-}$(as a proxy for water) in volcanic glass and nominally anhydrous minerals (NAMs). Samples were first analysed at the Carnegie Institute of Washington on their Cameca ims-6f with calibrations based on previous FTIR analyses. SHRIMP SI is a large geometry ion microprobe and is currently mainly used for $\mathrm{O}$ and $\mathrm{S}$ isotope analyses. The analytical protocol used here incorporates multiple collection of ${ }^{16} \mathrm{O}^{-}$and ${ }^{16} \mathrm{O}^{1} \mathrm{H}^{-}$allowing rapid measurements. A single calibration line incorporating all glasses and NAMs for the SHRIMP SI allows calibration of ${ }^{16} \mathrm{O}^{1} \mathrm{H}^{-} /{ }^{16} \mathrm{O}^{-}$to $\mathrm{H}_{2} \mathrm{O}$ over a wide range in concentration (50 to $15,000 \mathrm{ppm} \mathrm{H}_{2} \mathrm{O}$ ). This calibration line has around a $10 \%$ uncertainty, which appears to be limited only by sample heterogeneity. The current background for SHRIMP analysis is between 20-40 ppm but this is expected to improve with improved pumping on the source chamber.

A current limitation to water analysis of NAM samples, by any technique, is having a range of standard materials to enable $\mathrm{OH}^{-}$calibration to absolute $\mathrm{H}_{2} \mathrm{O}$ concentrations. Data are presented for 7 NAM samples ( 2 olivines, 2 orthopyroxenes and 3 clinopyroxenes) that appear to be promising as potential standards for international laboratory $\mathrm{H}_{2} \mathrm{O}$ measurements. These NAM samples have been analysed and characterised here by SHRIMP SI, FTIR, EMP and the Cameca ims-6f ion microprobe at CIW. Four of these samples have previously been measured by manometry to determine absolute $\mathrm{H}_{2} \mathrm{O}$ concentrations. 


\section{Introduction}

30 The analysis of water to low levels in glass inclusions of volcanic phenocrysts and, in recent years, 31 within the crystal structure of nominally anhydrous minerals (NAM), has facilitated a better 32 understanding of how water is recycled between the Earth's mantle, crust, and hydrosphere. ${ }^{1,2,3,4,5}$

34 Secondary ion mass spectrometry (SIMS) analysis is routinely used to measure water concentrations in 35 melt inclusions of volcanic phenocrysts, ${ }^{5,6}$ as well as volatile concentrations in NAM. ${ }^{7,8,9,10,11}$ Most of 36 this work is carried out on small geometry ion microprobes such as the Cameca ims $3 \mathrm{f}-7 \mathrm{f}$ models, 37 where the small source chamber volume, and hence minimal surface area, allows vacuum pressures of 38 the order of $5 \square 10^{-10}$ mbar to be obtained. It is well noted that low vacuum pressures are essential in obtaining low analytical backgrounds of water because water is a persistent species in vacuum to very 40 low pressures and in optimal circumstances water levels should be quantified down to sub $10 \mathrm{ppm}$ 41 levels. ${ }^{7}$ In contrast, large magnetic sector ion microprobes such as SHRIMP (Sensitive High 42 Resolution Ion MicroProbe) or Cameca 1280 have generally not been used for water measurements at 43 low abundances. In part this is due to the larger source chamber volume, which directly affects the 44 signal from desorbing-adsorbing water molecules from the target surface. Furthermore, the large mass 45 analyzers are difficult to tune for measurement of the $\mathrm{H}$ species $\left(\mathrm{H}^{-}\right.$or $\left.\mathrm{H}^{+}\right)$because of the long total 46 beam paths and interactions with the terrestrial magnetic field and/or other stray magnetic fields. 47 However, these large magnetic sector mass spectrometers have much higher inherent sensitivity at high 48 mass resolution and so pursuit of a viable analytical technique for water has advantages in terms of 49 signal strength at low water concentration.

51 Many of the ion microprobes being used for water analysis are dedicated to this task. This is to allow 52 optimal vacuum conditions to be maintained. To this end, metal (Indium) mounts are typically used 53 that present low inherent water to the vacuum system. On the other hand, epoxy mounts commonly 54 used for mounting small crystal grains have high inherent volatiles. Currently, SHRIMP SI is being 55 used mainly for stable isotope analysis. This involves introduction of a variety of glass and epoxy 56 mounts, which can therefore adversely affect the vacuum. Part of this work is to understand how we 
can increase the versatility of SHRIMP SI to allow a range of mounting materials into the vacuum system while still allowing us to do low level water analysis.

Fourier Transform Infra-Red spectroscopy (FTIR) is the most common technique used to determine water concentrations of glasses and minerals. Samples to be analysed by this technique need to be of such a dimension that allows wafers to be manufactured, typically around $100 \mu \mathrm{m}$ thick and doubly polished. The analytical area needs to be inclusion free and preferably be greater than $80 \times 80 \mu \mathrm{m}$ to allow precise absorbance measurements, depending on the thickness of the sample and for the FTIR analysis of water in small sample sets of anisotropic minerals, the samples need to be optically orientated. ${ }^{12}$ Microanalysis of $\mathrm{OH}$-stretching vibrations and molecular $\mathrm{H}_{2} \mathrm{O}$ in glasses or crystallographic $\mathrm{OH}^{-}$in minerals by FTIR can resolve water concentrations to less than 5 ppm in optimal circumstances using appropriate calibrations.

SIMS and FTIR methodologies are based on comparisons with reference materials and these require measurement of their absolute water concentrations. Few current reference materials for SIMS and FTIR have been independently measured and much of normalisation for water analysis is based on circular comparisons between SIMS and FTIR. As such there is a need for homogeneous standard materials of sufficient quantities that can be used routinely for calibration of both SIMS and FTIR. Reference materials are required to be homogeneous both on the analytical scale of SIMS and FTIR analysis, and on the scale of chips that could be distributed between laboratories.

In this paper, we present the first $\mathrm{H}_{2} \mathrm{O}$ measurements of natural glasses and silicate minerals using the large geometry ion microprobe SHRIMP SI and compare them directly to measurements made on the Carnegie Institution of Washington (CIW) Cameca ims-6f ion microprobe. These analyses are also compared to new FTIR measurements made at the Australian National University (ANU), as well as published FTIR and manometry measurements (e.g. ${ }^{13}$ ). The resulting database of SIMS and FTIR $\mathrm{H}_{2} \mathrm{O}$ analyses on geological materials are then used to discuss and make recommendations on the use of glass and NAM standards. 
89 Six natural basaltic glasses and seven NAM samples (consisting of two olivine, two orthopyroxene and three clinopyroxene mineral samples) were selected for analysis.

\section{BASALTIC GLASSES}

93 Naturally quenched basaltic glasses were obtained from the Fonualei Spreading Centre (ND-60, ND94 61), Mangatolo Triple Junction (ND70, ND69) and Manus Basin (24.1, 36.4). All glass samples have 95 been characterised for major and trace element geochemistry in the studies of Keller et al. ${ }^{14}$ for 96 Fonualei and Mangatolo samples and Sinton et al. ${ }^{15}$ for the Manus Basin samples. Our ND60, ND61, 97 ND69 and ND70 glass fragments were sourced from Richard Arculus (Australian National University) 98 and are subsamples from ocean-dredged rocks chosen as glass standards for the Cameca ims-6f facility at CIW (i.e., ND-60-01, ND70-01). ${ }^{16,17}$ ND-60, ND-61 and ND-69 samples used in this study contained quench inclusions of plagioclase. These were avoided in all types of analyses.

\section{NOMINALLY ANHYDROUS MINERALS}

103 Two olivine and five pyroxene samples were selected for analysis. Othropyroxene KBH-1 opx, an 104 aluminous enstatite from Kilbourne Hole, New Mexico and PMR-53, an augite megacryst from 105 Premier Mine, South Africa have had their water contents determined by manometry (KBH-1 opx: 217

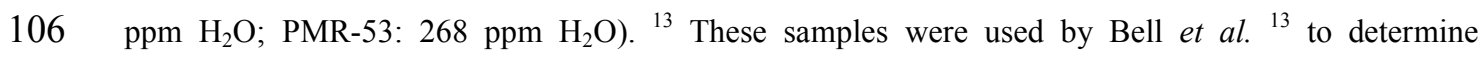
107 integrated absorption coefficients for O-H bonds in FTIR spectra of pyroxene minerals. Similarly, 108 clinopyroxene KBH cpx, also from Kilbourne Hole, New Mexico, was used in the FTIR study of Bell 109 and Rossman ${ }^{1}$ and has a manometry determined $\mathrm{H}_{2} \mathrm{O}$ content of $530 \mathrm{ppm} .{ }^{1}$ In addition, gem quality 110 natural samples of pyroxene and olivine were obtained from Russia, Pakistan, Tanzania and USA. The 111 Russian Cr-diopside is from an unidentified location in Russia, but does appear to be similar to the 112 Russian Cr-diopside used in the studies of Shannon et al., ${ }^{18}$ Ingrin et al. ${ }^{19,20}$ and sample $62047-70 \mathrm{~B}$ of 113 the recent Mosenfelder and Rossman study. ${ }^{11}$ The Pakistani olivine is from a pocket or vein located in 114 the shear zones of serpentinised dunitic rocks of Sapat, Kaghan Valley, Kohistan arc, Pakistan. Gem115 quality Pakistani olivine was obtained from the same location as was used in the studies of Gose et al. 
117 serpentine and/or needles of boron-bearing fibrous minerals (likely ludwigite-vonsenite, see Bouilhol et

118 al. ${ }^{24}$ ). These inclusions were avoided in all geochemical and infrared spectroscopy analyses of this 119 study. The Tanzania orthopyroxene is likely to be similar to the enstatite from Dodoma, Tanzania used 120 by Beran and Zemann ${ }^{25}$ and to the sample JLM46 in the recent study of Mosenfelder and Rossman. ${ }^{10}$ 121 San Carlos olivine samples are derived from xenoliths found within the Pliocene San Carlos alkali 122 basalt lava flow Arizona, U.S.A. We used two different samples of San Carlos olivine. San Carlos 1 is 123 a mm-sized cube of light green colour that was measured with EMP, IR and SIMS and appears similar 124 to those typically used for SIMS and FTIR studies. ${ }^{26,27}$ Additionally, the polarized IR spectra of an 125 unusually large crystal (>5 mm) with slightly darker colour (San Carlos 2) was analysed and compared 126 to those typically used for SIMS and FTIR studies. ${ }^{26,27}$

127

128 Sample preparation

129 The quality of the vacuum in the sample chamber is one of the most dominant factors that controls the 130 background for measurements of water by SIMS. Epoxy mounts continuously out-gas hydrocarbons 131 and water under vacuum and are therefore one of the largest contributors to the mass spectrometer 132 vacuum and hence ${ }^{16} \mathrm{O}^{1} \mathrm{H}^{-}$background measurements. In order to eliminate the epoxy contribution, 133 glasses and silicates were first polished in a Crystalbond embedding medium, then extracted with 134 acetone before being pressed into indium one-inch ion probe mounts (c.f. ${ }^{6}$ ). A single indium mount 135 was made that contained fragments of each of the samples. The mount was photographed in reflective 136 light and was then gold coated for SIMS analysis. After SIMS analysis, the mounts were lightly 137 polished with Al paste and carbon coated for electron-microprobe analysis.

139 Fragments of some of the same mineral and glass samples used for the ion probe study were analysed 140 by FTIR. Glass fragments were cut into wafers of around $3 \times 3 \mathrm{~mm}$, approximately $100 \mu \mathrm{m}$ thick, and 141 double polished using diamond and alumina compound. NAM grains were cut into tabular rhomboids 142 that measured between $1 \times 1 \mathrm{~mm}$ and $5 \times 5 \mathrm{~mm}$ after final polish. The olivine and orthopyroxene samples 143 were cut approximately parallel to the three crystallographic axes of the orthorhombic minerals before 144 being polished for FTIR analysis. The gem Cr-diopside was cut along three perpendicular sections that 145 were dictated by the cleavage of the pyroxene. 


\section{Experimental Techniques}

148

149

1. SENSITIVE HIGH RESOLUTION ION MICROPROBE - STABLE ISOTOPE (SHRIMP SI)

150

151 SHRIMP SI is a secondary ion mass spectrometer configured as an ion microprobe (Fig. 1) ${ }^{28}$ and is 152 one of three SHRIMP instruments housed in the Research School of Earth Sciences at The Australian 153 National University. SHRIMP SI was specifically designed for light isotope analysis, but it also has a 154 number of vacuum controls that enhance its capability for water analysis compared with other 155 SHRIMP instruments.

156

157 The main changes for SHRIMP SI compared to previous generation SHRIMP instruments are in and 158 around the source chamber with a goal of improving the vacuum. The SHRIMP SI source chamber is 159 machined out of a single piece of 316-grade stainless steel with differential pumping to the primary 160 column, to the quadrupole triplet system, and to the electron column (Fig. 1). Internal stage motors 161 have been replaced by a bellows system with external drives. The vacuum interlock consists of a two162 stage system with the inner lock having a UV lamp to enhance water excitation from the sample 163 surface.

164

165 The source chamber is pumped with a Varian 300 1/s ion pump with a Ti sublimation unit. This 166 pumping system was chosen for its low ultimate vacuum pressure, and lack of mechanical vibration 167 that could affect sample stability. During analyses,, the sample chamber vacuum pressure was 168 measured to be between 7 and $9 \times 10^{-9} \mathrm{mbar}$ as indicated by an ion gauge in the source chamber, while 169 the current passing through the ion pump is consistent with pressures around 1-3 x 10 $0^{-9}$ mbar.

170

171 The primary ion beam for SHRIMP SI is $\mathrm{Cs}^{+}$that is generated in a Kimball Physics model IGS-4 ion 172 gun with $\mathrm{Cs}^{+}$zeolite as the emitter. $\mathrm{Cs}^{+}$ions are initially focused through an accelerating potential of 5 $173 \mathrm{kV}$ in the gun. The $\mathrm{Cs}^{+}$beam is focused to the Kohler aperture, which is located at the focal point of the 174 final einzel lens. This lens operates as an immersion lens to accelerate the beam to sample potential 175 (providing an additional $10 \mathrm{keV}$ giving a total beam energy at the target of $15 \mathrm{keV}$ ), and to demagnify 
176 the Kohler aperture by a factor of 10 on to the sample surface. Thus a $200 \mu \mathrm{m}$ Kohler lens produces a

$17720 \mu \mathrm{m}$ "spot".

178

179 Sputtering with a primary $\mathrm{Cs}^{+}$beam results in charge build up owing to the delivery of a positively

180 charged primary beam, and extraction of negative secondary ions (and electrons). In order to neutralise

181 charging, electrons are focused from the Kimball electron gun (model ELG-2) to the surface at a $45^{\circ}$

182 incidence angle and with a final energy of around $1.5 \mathrm{keV}$. The electron column operates with a quasi-

183 Kohler illumination system in order to improve the uniformity of illumination.

184

185 Negative secondary ions are accelerated from the $-10 \mathrm{kV}$ sample potential via an initial $800 \mathrm{~V}$ potential

186 difference to the extraction plate. A feature of the SHRIMP SI design is a vertical and horizontal beam-

187 steering capability on the extraction plate. The beam is then accelerated to real ground and beam

188 transmission is maximized to the source slit with a symmetric (circular aperture) einzel lens system

189 followed by the standard quadrupole-triplet lens system used on SHRIMP II.

190

191 SHRIMP SI uses the same forward-geometry as SHRIMP-II instruments with a double-focusing mass

192 analyzer design ${ }^{29}$ to enable high mass resolution (5500 M/ $\Delta \mathrm{M}$ at $10 \%$ peak width for $100 \mu \mathrm{m}$ entrance

193 and exit slits) while maintaining high sensitivity through a physically large mass spectrometer (magnet

194 turning radius of $1000 \mathrm{~mm}$ ). SHRIMP-SI was originally designed with a three-head multiple collector;

195 ions can be measured in Faraday cups, or with interchangeable electron multipliers. The multiple

196 collector has since been modified to incorporate a fourth detector for measuring ${ }^{33} \mathrm{~S}$ in four-sulfur

197 isotope measurements. ${ }^{30}$ During analysis the pressure in the mass analyser and collector is in the range

198 of 1 to $3 \times 10^{-8}$ mbars. At these pressures only minor ion scattering is produced and therefore there is

199 minimal contribution to the ${ }^{16} \mathrm{O}^{1} \mathrm{H}^{-}$background..

200

201 The multiple collector was configured to allow simultaneous measurement of ${ }^{16} \mathrm{O}$ and ${ }^{16} \mathrm{O}^{1} \mathrm{H}^{-}$. For $202{ }^{16} \mathrm{O}^{1} \mathrm{H}^{-}$, a $100 \mu \mathrm{m}$ collector slit was used to achieve high mass resolution $(5,500 \mathrm{M} / \Delta \mathrm{M})$ sufficient for 203 full resolution of ${ }^{17} \mathrm{O}$ and ${ }^{16} \mathrm{O}^{1} \mathrm{H}^{-}$(Fig. 2). For ${ }^{16} \mathrm{O}$ on the low mass head a $400 \mu \mathrm{m}$ collector slit was 204 used (ca. $1250 \mathrm{M} / \Delta \mathrm{M}$ ). The low resolution provides a broad flat top peak for ${ }^{16} \mathrm{O}$ so any differential 
205 movement of ${ }^{16} \mathrm{O}$ from ${ }^{16} \mathrm{O}^{1} \mathrm{H}^{-}$does not affect the ${ }^{16} \mathrm{O}$ beam intensity. During data acquisition, the

$206{ }^{16} \mathrm{O}^{1} \mathrm{H}^{-}$peak is centred, or if ${ }^{16} \mathrm{O}^{1} \mathrm{H}^{-}$is very low, ${ }^{17} \mathrm{O}$ is centred followed by a peak jump to ${ }^{16} \mathrm{O}^{1} \mathrm{H}^{-}$.

207

208 SHRIMP analyses have been performed with ${ }^{16} \mathrm{O}^{1} \mathrm{H}^{-} /{ }^{16} \mathrm{O}^{-}$in order to allow the water concentration to 209 be assessed with a static magnet position in multiple collection mode. This mode facilitates data 210 collection and analysis with no need for time interpolation of the signals. There is potentially some 211 ambiguity in the $\mathrm{O}^{-}$signal in that some of that signal could be sourced from molecular break up of $212{ }^{16} \mathrm{O}^{1} \mathrm{H}^{-}$during sputtering. However this is expected to be a very small component because all of the 213 targets are silicates with large ${ }^{16} \mathrm{O}^{-}$signals. Furthermore it is essentially removed by the calibration 214 provided there is a consistent dissociation of ${ }^{16} \mathrm{O}^{1} \mathrm{H}^{-}$at differing concentrations.

215

216 Prior to insertion in to SHRIMP SI, the mount contained in the mount holder was placed in a vacuum 217 oven overnight, and the mount was pumped down in the sample lock for 24 hours prior to analysis. A 218 spot size of $30 \mu \mathrm{m}$ was used for analysis. The primary beam was first rastered over the spot area for 219120 seconds to remove gold and any surface contamination. The beam was then stabilised for 60 220 seconds prior to an automated beam alignment procedure. Five static analyses of ${ }^{16} \mathrm{O}^{1} \mathrm{H}^{-} /{ }^{16} \mathrm{O}^{-}$were 221 acquired, each consisting of ten sequential 2-second integrations, with a total time of analysis 222 (including background) of 320 seconds. Measurement errors less than 5\% were taken as indicative of a 223 homogenous water concentration within the analysis. Analyses that showed heterogeneity with depth 224 within a single sputter crater were discarded.

226 Determining the absolute sensitivity for water analyses on SHRIMP SI is not straightforward because 227 the electron beam signal dominates over the primary beam and secondary ion beam. Our best estimate 228 for the primary beam intensity used in this work is around $5 \mathrm{nA}$ and is similar to that reported by Ickert 229 et al. ${ }^{31}$ for oxygen isotope analysis. ${ }^{31}$ Sensitivity of ${ }^{16} \mathrm{O}^{1} \mathrm{H}^{-}$analyses on the SHRIMP SI is estimated at $230170 \mathrm{c} / \mathrm{s} / \mathrm{ppm} \mathrm{H}_{2} \mathrm{O}$ yielding a sensitivity of approximately ca. $35 \mathrm{cps} / \mathrm{ppm} \mathrm{H}_{2} \mathrm{O} / \mathrm{nA}$. This is substantially 231 higher than the sensitivity reported for the CIW Cameca of $\left(2 \mathrm{cps} / \mathrm{ppm} \mathrm{H}_{2} \mathrm{O} / \mathrm{nA}\right)^{6}$ and is in accord with 232 the transmission estimated from Ti isotope analysis. ${ }^{32,33}$

233

\section{2. CAMECA IMS-6F}


236 Methods employed to measure the concentrations of water with the Cameca ims-6f ion microscope at 237 the Carnegie Institution of Washington were similar to those developed for the micro-analysis of trace 238 concentrations of volatiles in glasses and NAMs by Hauri et al. ${ }^{6,8}$ and Koga et al. ${ }^{7}$ Pressure in the ion 239 probe sample chamber was $<8 \times 10^{-10}$ mbar during all analyses. Background limits $\left(<10 \mathrm{ppm}_{2} \mathrm{O}\right)$ 240 were determined by the repeated analysis of synthetic anhydrous forsterite and anhydrous quartz 241 (Suprasil 3002, 1 ppm $\mathrm{H}_{2} \mathrm{O}$, available from Heraeus Quarzglas) located in each sample mount. The 242 background of $\mathrm{H}_{2} \mathrm{O}$ is relatively minor compared to all glasses and most NAM analyses studied here 243 (with the exception of San Carlos olivine) and therefore no background correction was made. Before 244 each analysis, the secondary ion images of ${ }^{16} \mathrm{O}^{1} \mathrm{H}^{-}$were projected on to the channel plate in ion 245 microscope mode. This helped to avoid inclusions and cracks, which appear as bright features on the 246 projected image. After each beam spot was carefully examined, the field aperture was inserted to 247 permit transmission of ions only from the central $8 \mu \mathrm{m}$ of the $20 \mu \mathrm{m}$ beam crater, thus avoiding 248 transmission of ${ }^{16} \mathrm{O}^{1} \mathrm{H}^{-}$from the edge of the sputter crater and the surface of the sample. The use of this 249 small field aperture reduces the transmission of ions and thus the sensitivity compared with the 250 SHRIMP SI, but is crucial for obtaining low detection limits. Rastering of the primary beam over a 50 $251 \mu \mathrm{m}$ by $50 \mu \mathrm{m}$ area for 120 seconds was also performed to remove any surface contamination prior to 252 each analysis. Water analyses are based on the ${ }^{16} \mathrm{O}^{1} \mathrm{H}^{-}{ }^{30} \mathrm{Si}^{-}$ratio measured through cyclically peak253 stepping the magnet.

254

255 A range of basaltic glasses and NAM standards are used by CIW to define calibration curves of $\mathrm{H}_{2} \mathrm{O}$ 256 contents from ${ }^{16} \mathrm{O}^{1} \mathrm{H}^{-}{ }^{30} \mathrm{Si}^{-} .{ }^{6,7,8,17} \mathrm{ND}$-glasses as well as PMR-53 cpx and $\mathrm{KBH}$-opx samples described 257 here are used to constrain the calibration curves for glass, clinopyroxene and orthopyroxene, 258 respectively.

259

\section{FOURIER TRANSFORM INFRARED SPECTROSCOPY}

262 Fourier Transform infrared (FTIR) spectroscopy analysis was conducted at the Research School of 263 Earth Sciences at The Australian National University, using a Bruker IFS28 spectrometer coupled to a 264 Hyperion 1000 microscope that is equipped with a nitrogen-cooled MCT detector. The sample stage is 
265 housed in a Perspex chamber that is continuously flushed with dry air in order to suppress the 266 background of atmospheric water. Doubly polished glass wafers were investigated with unpolarised 267 transmission FTIR using a 50-100 $\mu \mathrm{m}$ square aperture. The glasses were incrementally thinned to 268 optimise the intensity of the absorption for the $3570 \mathrm{~cm}-1^{-1}$ band. The thickness of the samples was 269 determined with a Mitutoyo mechanical device, which is accurate to 3-4 $\mu \mathrm{m}$ and were found to be 270 between 80 and $200 \mu \mathrm{m}$ thick. The gem olivine and orthopyroxene samples were analysed with 271 polarised IR light (KRS 5 polarizer) along the three crystallographic axes whereas the clinopyroxene 272 was analysed along three perpendicular axes that are close in orientation to the crystallographic axes.

273 The spectra were acquired in the range of 5500 to $600 \mathrm{~cm}^{-1}$ as the average of 64-128 scans with a 274 resolution of $4 \mathrm{~cm}^{-1}$. The atmospheric compensation tool from the OPUS ${ }^{\circledR}$ software was applied to all 275 spectra to minimise absorption bands related to atmospheric water. The background correction was 276 implemented by the interactive concave rubber band correction with 64 baseline points and three 277 iterations of the OPUS ${ }^{\circledR}$ software for olivine and glasses. For pyroxenes, the background was corrected 278 using a manual spline fit as described by Mosenfelder and Rossman ${ }^{10,11}$ (see Supplementary file A1 279 for raw and baseline corrected spectra for olivine and pyroxenes measured in this work).

280

\section{ELECTRON MICROPROBE}

282

283 Mineral and glass samples were analysed on a Cameca SX100 electron microprobe in the Geochemical 284 Analysis Unit at Macquarie University, Australia. An accelerating voltage of $15 \mathrm{keV}$ was used with a 285 focused beam current of $20 \mathrm{nA}$. A counting time of 10 seconds was assigned to both peak and 286 background measurements. Spectrometer calibration was achieved using the following standards: albite $287 \mathrm{(Na})$, hematite $(\mathrm{Fe})$, kyanite $(\mathrm{Al})$, olivine $(\mathrm{Mg})$, chromium $(\mathrm{Cr})$, spessartine garnet $(\mathrm{Mn})$, orthoclase $(\mathrm{K})$, 288 wollastonite $(\mathrm{Ca}, \mathrm{Si})$ and rutile $(\mathrm{Ti})$.

\section{Results}

291

\section{Electron microprobe}

293 
294 Compositions for both the basaltic glasses and mineral samples analysed in this study are presented in

295 Table 1. Replicates $(\mathrm{n}=7)$ show that all grains are relatively homogenous with standard deviations for 296 major elements in each sample typically being less than $1 \%$ (1 sigma S.D; Table 1). Major element 297 compositions for many of the NAMs are similar to those in previously published studies on these 298 minerals (PMR-53 cpx, KBH-opx: ${ }^{13} \mathrm{KBH}-\mathrm{cpx}:{ }^{1}$ Rus Cr-diop: ${ }^{19,20}$ Tan-opx: ${ }^{25}$ ). The Pakistani olivine 299 sample with a $\mathrm{Mg} \#$ of 95 has a higher $\mathrm{MgO}$ and lower $\mathrm{FeO}^{\mathrm{t}}$ (Table 1) than the grain analyses in the 300 Gose et al. ${ }^{22}$ study and is situated at the upper end of the range of Mg\# (89-97) reported by Bouilhol et 301 al. ${ }^{24}$

302

Infrared Spectroscopy - glass samples

304

305 The glass samples are characterised by a large broad absorption band at $3700-2800 \mathrm{~cm}^{-1}$ (Fig. 3) and a 306 smaller band at $1630 \mathrm{~cm}^{-1}$. The broad band is attributed to the combination of molecular water $\left(\mathrm{H}_{2} \mathrm{O}\right)$ 307 that can fill in larger cavities in the silicate network of glasses and $\mathrm{OH}^{-}$that is strongly associated with 308 non-bridging oxygen. ${ }^{34,35,36}$ The smaller band at $1630 \mathrm{~cm}^{-1}$ is attributed to molecular water alone. The 309 linear absorptions at $3370 \mathrm{~cm}^{-1}$ and at $1630 \mathrm{~cm}^{-1}$ combined with the extinction coefficients for Fe310 bearing andesites from Mandeville et al., ${ }^{37}$ were used to quantify the total and molecular water 311 contents, respectively (Table 2 and 3). Typically 10 analyses were performed on each glass sample. 312 The standard deviation of these multiple analyses varies from $0.5-3 \%$. Combined with an uncertainty of $3132-5 \%$ in the thickness of the samples and $5 \%$ uncertainty in the density of the glasses the total 314 uncertainty on water contents is $5.5-7.7 \%$ when the individual uncertainties are added in quadrature.

315

316 Infrared Spectroscopy - NAM samples

317

318 Orientated polarised FTIR analyses of the Russian Cr-diopside (Rus Cr-diop), Pakistani olivine (Pak 319 ol), Tanzanian orthopyroxene (Tan opx) and San Carlos olivine (San Carlos) were undertaken and the 320 results are shown in Fig. 4. The position of the several hydroxyl-stretching bands for individual 321 samples is also given in Fig. 4. Tan opx shows two groups of bands which are highly polarized along 322 the g optical axis (corresponding to the c-axis for orthopyroxene), the most intense ones are located 323 between 3400 and $3560 \mathrm{~cm}^{-1}$, whereas broad bands are found in the range from $\sim 2800-3400 \mathrm{~cm}^{-1}$. Rus 
324 Cr-diop shows two main bands at 3646 and $3430 \mathrm{~cm}^{-1}$ with similar absorbances close to $\square$ and

325 optical axes. Band position and degree of polarization for Tan opx and Rus Cr-diop are similar to those 326 commonly found in pyroxenes. ${ }^{10,11}$ Despite the low water content the IR spectra for San Carlos-2 is 327 exceptionally well resolved in the large investigated sample $(6.34 \times 6.45 \times 7.89 \mathrm{~mm})$. IR spectra for 328 San Carlos olivine is considered to be representative of the upper mantle. It is strongly polarized along 329 the $\square$ direction (a-axis) being the two main bands located at 3572 and $3525 \mathrm{~cm}^{-1}$. OH-stretching bands 330 corresponding to trivalent substitution (ca. $3350 \mathrm{~cm}^{-1}$, Berry et al. ${ }^{38}$ ) are lacking. In the smaller, mm331 sized cube no clear IR absorbance could be observed. Pak olivine shows a particularly unusual IR 332 spectra with maxima in absorbances along the $\square$ and b optical axes. Band position and polarization 333 measured in Pak olivine is similar to the ones reported by Ingrin et al. ${ }^{39}$ Kovács et al. ${ }^{23}$ Gose et al. ${ }^{22}$

334 The recent study of Ingrin et al. ${ }^{39}$ showed that the OH-stretching bands of the Pakistani olivine at 335 approximately 3700 and $3598 \mathrm{~cm}^{-1}$ are associated with B-H coupled substitution and that these peaks 336 are superimposed on $(4 \mathrm{H})_{\mathrm{si}}$ defects that result in bands at 3612,3580 and $3566 \mathrm{~cm}^{-1}$ as well as the broad $337 \mathrm{OH}$-stretching band associated with interstitial $\mathrm{OH}^{-}$at 3549 and $3568 \mathrm{~cm}^{-1}$. The sample that we 338 analysed is missing the relatively minor $\mathrm{OH}$-stretching band associated with $\mathrm{B}-\mathrm{H}$ at $3521 \mathrm{~cm}^{-1}$. All 339 investigated samples are free of signals from hydrous inclusions (such as serpentine or amphiboles).

341 The concentrations of $\mathrm{H}_{2} \mathrm{O}$ in NAMs were quantified combining the total integrated absorption of 342 bands in the $3750-2800 \mathrm{~cm}^{-1}$ region (see notes in Table 4, for details of the integration range for 343 different minerals), the density, thickness of the samples and specific absorption coefficients. The total 344 integrated absorption $\left(\mathrm{Abs}_{\mathrm{tot}}\right)$ was obtained by adding the polarized measurements along the three 345 crystallographic axes (orthopyroxene, olivine) or three perpendicular orientations (clinopyroxene). The 346 absorption coefficient of Bell et al. ${ }^{13}$ for orthopyroxenes $\left(\mathrm{k}=0.067 ; \mathrm{H}_{2} \mathrm{O}(\mathrm{ppm} w \mathrm{w})=\mathrm{k} \times \mathrm{Abs}_{\mathrm{tot}}\right.$ 347 (integrated per $\mathrm{cm})$ ) and clinopyroxene $(\mathrm{k}=0.141)$ were used here to be consistent with study of Koga 348 et al. ${ }^{7}$ For olivine the absorption coefficient $(\mathrm{k}=0.188)$ from Bell et al. ${ }^{40}$ is given in Table 4 and for 349 the Pakistani olivine also the absorbtion coefficient $(\mathrm{k}=0.57)$ of Kovács et al. ${ }^{23}$ was used because 350 unlike the other NAMs studied here, there is a large difference between the FTIR (using Bell et al. ${ }^{40}$ 351 calibration) and ion-probe water contents (based on the calibrated analysis from the Cameca ims 6f; 352 Table 4). The Pakistani olivine is from hydrothermal veins of serpentinised dunitic rocks whereas the 353 samples used in the Bell et al. ${ }^{40}$ study are from pressure and temperature conditions similar to the 
354 mantle environment. The use of the Bell et al. ${ }^{40}$ absorption coefficient for the FTIR calibration is 355 therefore not necessarily valid for the Pakistani olivine. Ingrin et al. ${ }^{39}$ showed that the proposed 356 absorption coefficient from Kovacs et al. ${ }^{23}$ of $0.57 \pm 0.04$ is better suited for the Pakistani olivine than 357 the generic absorption coefficient of $0.188 \pm 0.012$ determined by Bell et al. ${ }^{40}$ Encouragingly by using 358 the Kovacs et al. ${ }^{23}$ absorption coefficient the calculated water content of the Pakistani olivine from our 359 FTIR analyses is almost identical to that measured by CIW ion-probe (Table 4). The error on the water 360 content has been determined by adding in quadrature the uncertainty in thickness $(5 \%)$, the total 361 absorbance (5\%) and the absorption coefficient (10\%).

362

\section{Ion probe analyses}

364

365 A subset of ND-glasses as well as fragments of PMR-53 cpx and KBH-opx are used as standards on 366 the CIW Cameca ims-6f to constrain the calibration curves for glass, clinopyroxene and orthopyroxene, 367 respectively. $\mathrm{H}_{2} \mathrm{O}$ contents of the samples have been determined using the calibration curves based on 368 previous FTIR measurements and are presented here for comparison (Table 2). Estimated water 369 contents for the basaltic glasses and pyroxene grains are similar to those found by FTIR in this study 370 (Table 2). The errors associated with these estimates are approximately $10 \%$ for glass and $20 \%$ for 371 olivine and pyroxene. ${ }^{7}$

372

373 Cameca ims-6 $\mathrm{f}_{2} \mathrm{O}$ data are plotted against the Manometry-FTIR data in the standard materials in Fig. 374 5. The data for the glasses appear well correlated (Fig. 5(a)). For the NAMs the samples show a good 375 overall correlation although the water content for PMR-53 appears to be high relative to the other 376 minerals (Fig. 5(b)). The Pakistani olivine shows uniform composition by SIMS as opposed to the 377 significant spread in the FTIR data. An unweighted line-fit has a slope of 1.02, a y-axis intercept of 180 378 ppm $\mathrm{H}_{2} \mathrm{O}$, and $\mathrm{r}$ of 0.996 (Fig. 5(a)). The near-unity slope indicates a good correspondence between 379 the methodologies used for analysis as well as consistency with the previously used calibration factors. 380 The high y-axis intercept is notable and is due to the poor fit to the low $\mathrm{H}_{2} \mathrm{O}$ NAMs (see Fig. 5(b)). The 381 unweighted regression places effectively equal emphasis on all data and the discrepancy is notable for 382 the low $\mathrm{H}_{2} \mathrm{O}$ materials because of the expansion of the scale and the limited range of the data in 383 absolute terms. A better fit is produced by a weighted-line (from Isoplot 3$)^{41}$ with weighting based on 
384 the measurement uncertainty/dispersion. The weighted line fit has a slope of $1.073 \pm 0.058(95 \%$

385 confidence limit) and an intercept of $6 \pm 17 \mathrm{ppm} \mathrm{H}_{2} \mathrm{O}$ (95\% c.1.), and an MSWD of 5.6. The weighted

386 line fit provides a much better correspondence to the data from the NAMs (Fig. 5(b)).

387

388 The ${ }^{16} \mathrm{O}^{1} \mathrm{H}^{-}$background of SIMS analysis can be assessed directly through the analysis of the fragment 389 of Suprasil glass that is pressed into the mounts. The ${ }^{16} \mathrm{O}^{1} \mathrm{H}^{-}$signal emanating from the glass is 390 expected to be dominated by water in the vacuum absorbing on to the target surface. An example of the 391 temporal evolution of ratios of ${ }^{16} \mathrm{O}^{1} \mathrm{H}^{-} /{ }^{30} \mathrm{Si}^{-}$measured on the Cameca ims-6f from the Suprasil glass in 392 the course of this work are provided in Supplementary file A2/Cameca Dataset 2. Neither SHRIMP $393{ }^{16} \mathrm{O}^{1} \mathrm{H}^{-} /{ }^{16} \mathrm{O}^{-}$nor Cameca ${ }^{16} \mathrm{O}^{1} \mathrm{H}^{-} /{ }^{30} \mathrm{Si}^{-}$data sets have been corrected for the background measured on 394 the Suprasil glass in order to better evaluate the respective data sets. For the Cameca data, the initial $395{ }^{16} \mathrm{O}^{1} \mathrm{H}^{-} /{ }^{30} \mathrm{Si}^{-}$value for the Suprasil glass is $3.7 \times 10^{-3}$ and this falls to $6.6 \times 10^{-4}$ during the analytical 396 session as water is actively pumped from the source chamber. This corresponds to a change in the 397 effective background expressed as water concentration from $37 \mathrm{ppm}$ to $7 \mathrm{ppm}$ for the San Carlos 398 olivine calibration in Table 2. Consistent with the higher source-chamber vacuum pressure in 399 SHRIMP SI, analyses of the Suprasil glass show a range in ${ }^{16} \mathrm{O}^{1} \mathrm{H}^{-} /{ }^{16} \mathrm{O}^{-}$values from 2 to $4 \times 10^{-5}$ 400 (approximately 40 to $80 \mathrm{ppm}_{2} \mathrm{O}$ for the San Carlos olivine grain). The data illustrated in Fig. 6 were 401 obtained in a session with a background ${ }^{16} \mathrm{O}^{1} \mathrm{H}^{-} /{ }^{16} \mathrm{O}^{-}$of around $2 \times 10^{-5}$ as measured on Suprasil glass.

402

403 The ${ }^{16} \mathrm{O}^{1} \mathrm{H}^{-}{ }^{16} \mathrm{O}^{-}$ratios and the ${ }^{16} \mathrm{O}^{1} \mathrm{H}^{-}{ }^{30} \mathrm{Si}^{-}$ratios of each of the glasses and NAM grains from the 404 Cameca ims-6f and SHRIMP SI respectively are presented in Table 2 and illustrated in Fig. 6; analyses 405 from different sessions are given in the supplementary file A2. The glass data are well correlated (Fig. 406 6(a)). An unweighted line fit between the Cameca ${ }^{16} \mathrm{O}^{1} \mathrm{H}^{-}{ }^{30} \mathrm{Si}^{-}$and SHRIMP $\mathrm{SI}^{16} \mathrm{O}^{1} \mathrm{H}^{-} /{ }^{16} \mathrm{O}^{-}$has a line 407 of slope 0.000793 and intercept of $3.7 \times 10^{-5}$ with an $\mathrm{r}$ parameter of 0.9996 , indicating a near perfect 408 correlation between the two data sets. However, like the Cameca vs the FTIR/manometry data 409 described above, the unweighted line fit has a y-axis intercept that appears high relative to the 410 distribution of the data (Fig. 6(b)). The weighted line fit has a slope of $0.000832 \pm 0.000044$ (95\% conf. 411 limit), with an intercept of $2.8 \pm 0.3 \times 10^{-5}$ and an MSWD of 19. The weighted-line-fit therefore has a 412 lower intercept value than the unweighted-line-fit and produces a better fit to the NAMs data (Fig. 413 6(b)). The MSWD value suggests significant scatter in the data set and this is most apparent in the 
414 NAMs data (Fig. 6(b)), where high precision (and limited dispersion) is coupled with significant scatter

415 around the best-fit line.

416

417 These regressions show that there is significant sensitivity of the line-fits to the data sets used. If the 418 glass data were to be used alone a non-zero intercept would not be surprising given the large 419 extrapolation towards the y axis. On the other hand, the NAMs data has limited spread and is being 420 affected by the water background. As noted above, SIMS is a matrix sensitive technique and so 421 independent calibration of glass and the specific minerals is potentially desirable. However, this yields 422 calibration lines that are underdetermined in that only two or three samples are used for NAMs, and 423 even in the glasses there is significant dispersion in several of the samples and the line is dominantly constrained by the extreme values.

425

426 If the data are fitted through the analyses of both glass and NAMs, a well-constrained line is 427 determined (Fig 6(a) and 6(b)). This is perhaps not as surprising as it would seem in that it only 428 requires relative consistency in sputtering and ionisation of ${ }^{16} \mathrm{O}^{1} \mathrm{H}^{-} /{ }^{16} \mathrm{O}^{-}$and ${ }^{16} \mathrm{O}^{1} \mathrm{H}^{-}{ }^{30} \mathrm{Si}^{-}$of the samples 429 between SHRIMP SI and the Cameca ims-6f respectively. The good fit in the calibration line simply 430 indicates that this consistency holds between different SIMS instruments notwithstanding possible 431 systematic matrix effects affecting the absolute water determination.

432

433 The internal reproducibility of the SHRIMP analyses appears to be similar to that measured on the 434 Cameca ims-6f. While the SHRIMP reproducibility for the glasses [expressed as $1 \sigma /\left({ }^{16} \mathrm{O}^{1} \mathrm{H}^{-} /{ }^{16} \mathrm{O}^{-}\right) * 100$ 435 in Table 2] is the highest for ND61 at $1.4 \%$, the variability of ${ }^{16} \mathrm{O}^{1} \mathrm{H}^{-}{ }^{30} \mathrm{Si}^{-}$for 36.4 is $5.3 \%$, and the 436 other glasses have reproducibilities better than $2 \%$. The differences between the means of SHRIMP 437 data and the means of the Cameca data appear to be consistent within ca. $10 \%$ for the glasses as given 438 by the deviations from the correlation line (Fig. 6(a)).

440 In comparison, the NAMs measured by SHRIMP SI show greater variability, up to $5 \%$, while the 441 Cameca data only vary over a range of up to $3 \%$, not including the San Carlos olivine sample that 442 shows variability at $35 \%$. There appears to be greater dispersion in the analyses than would be 443 predicted from the internal reproducibility. Nevertheless, excluding the lowest values for Tan-opx and 
444 San Carlos olivine, the SHRIMP and Cameca data appear to correlate within a range of ca. $20 \%$ (Fig.

$4456(b))$.

446

447 The main difference between the Cameca ims-6f data and the SHRIMP data is an elevated ${ }^{16} \mathrm{O}^{1} \mathrm{H}^{-}$ 448 background in the SHRIMP analyses beyond that expected from measurement of Suprasil glass. A 449 case in point for the SHRIMP data is the comparison of Suprasil glass $\left({ }^{16} \mathrm{O}^{1} \mathrm{H}^{-} /{ }^{16} \mathrm{O}^{-} \approx 2 \times 10^{-5}\right)$ and the 450 San Carlos olivine $\left({ }^{16} \mathrm{O}^{1} \mathrm{H}^{-} /^{16} \mathrm{O}^{-} \approx 4 \times 10^{-5}\right)$ where both samples should have $<10 \mathrm{ppm}$ water and 451 therefore the measured ${ }^{16} \mathrm{O}^{1} \mathrm{H}^{-} /{ }^{16} \mathrm{O}^{-}$should be dominated by the contribution from vacuum $\mathrm{H}_{2} \mathrm{O}$. 452 Possible sources of this discrepancy could be related to sample preparation and mount degassing prior 453 to introduction to the SHRIMP vacuum system, or to matrix effects affecting either production of $454{ }^{16} \mathrm{O}^{1} \mathrm{H}^{-}$or ${ }^{16} \mathrm{O}^{-}$from the glass and olivine targets.

455

456 In order to check the behaviour of these materials after sustained vacuum pumping, two mounts 457 comprising a $25 \mathrm{~mm}$ diameter quartz glass disk (Ted Pella, Inc. Product No.16001-2) and a polished 458 metal mount containing San Carlos olivine were placed in the source chamber. After overnight 459 pumping (source chamber pressure reading $9 \times 10^{-9}$ mbar), the ${ }^{16} \mathrm{O}^{1} \mathrm{H}^{-} /{ }^{16} \mathrm{O}^{-}$values were consistent with 460 those measured above. After 6 days in the source chamber (pressure reading $7 \times 10^{-9}$ mbar), the San 461 Carlos olivine had fallen to an ${ }^{16} \mathrm{O}^{1} \mathrm{H}^{-} /{ }^{16} \mathrm{O}^{-}$of $2 \times 10^{-5}$ while the quartz glass had remained unchanged 462 at ${ }^{16} \mathrm{O}^{1} \mathrm{H}^{-} /{ }^{16} \mathrm{O}^{-}$of $2 \times 10^{-5}$. As such it appears that the apparent background equilibrated for the two 463 targets after 6 days within the sample chamber. It may be that water sticks to the olivine more 464 aggressively than quartz and some care must be exercised that the olivine has dissipated the surface 465 water prior to analysis. It would also suggest that care should be taken in assessing the level of the 466 background ${ }^{16} \mathrm{O}^{1} \mathrm{H}^{-} /{ }^{16} \mathrm{O}^{-}$based on Suprasil analyses or San Carlos olivines alone.

467

468 In Figure 7 the SHRIMP ${ }^{16} \mathrm{O}^{1} \mathrm{H}^{-} /{ }^{16} \mathrm{O}^{-}$data have been background corrected and plotted against the 469 manometry/FTIR data in Table 2. The calibration is performed with a weighted best-fit to all data i.e. 470 glasses, pyroxenes and olivines. The calibration line between SHRIMP ${ }^{16} \mathrm{O}^{1} \mathrm{H}^{-} /{ }^{16} \mathrm{O}^{-}$and the 471 manometry/FTIR $\mathrm{H}_{2} \mathrm{O}$ values has a slope of $1.916 \pm 0.062 \times 10^{-7}$, an intercept of $3.2 \pm 5.3 \times 10^{-6}$ and an 472 MSWD of 14. Given the goodness of the fit, there is little in our data to warrant an individual 473 calibration for the different phases at this stage. Of interest here is the apparently high water content of 
474 the San Carlos olivine at $\approx 80 \mathrm{ppm}$. If the Suprasil glass is used for background correction, this would

475 still leave a concentration of $\approx 40 \mathrm{ppm} \mathrm{H}_{2} \mathrm{O}$. But, as noted above, this is a direct artefact of insufficient

476 pump down and vacuum equilibration prior to analysis. However, there is little to suggest the Pakistani

477 olivine has a high background contribution and so the issue with San Carlos olivine may not be a

478 simple mineralogical effect. Moreover, there is no indication in the Tan opx for a residual background

479 effect. At this stage it appears that care will be needed in assessing SHRIMP SI data from NAMs with

$480 \mathrm{H}_{2} \mathrm{O}$ concentrations less than $100 \mathrm{ppm}$. In contrast, the water concentrations in volcanic glasses are

481 well constrained by the combined calibration fit between glasses and NAMs.

482

\section{Discussion}

484

485

\section{$\mathrm{H}_{2} \mathrm{O}$ analyses}

486

487 The excellent agreement between data collected on the SHRIMP SI and data collected on the CIW

488 Cameca ims-6f indicates that both instruments produce ions in a similar way and respond to different

489 matrices in the same way. The main difference between the two data sets pertains to the higher

490 apparent water background in the SHRIMP SI. This is not unexpected given the larger volume of the

491 source chamber and the significantly higher pressure in the SHRIMP SI source chamber.

492

493 The agreement between analyses performed by SHRIMP SI and CIW Cameca ims-6f show that the

494 standard materials are reasonably homogeneous over the surfaces of the materials that have been

495 analysed. In comparison, the manometry-FTIR (M-FTIR) data of Table 2 typically show variability at

496 the 10\% level (excluding San Carlos olivine). The discrepancy between M-FTIR and the Cameca $\mathrm{H}_{2} \mathrm{O}$

497 concentrations for the glasses ranges up to 20\%, with the largest discrepancy for glass 24.1 (3900 ppm

498 by Cameca/SHRIMP SIMS, 3100 ppm by M-FTIR). This agreement appears to be consistent with

499 previous conclusions that these glasses have water distributed reasonably uniformly throughout. It

500 should again be reinforced that M-FTIR analysis is based on a bulk measurement, whereas SIMS

501 analysis consumes a very small amount of material at a surface. As such, the agreement between the

502 two SIMS techniques is perhaps to be expected as the same samples are effectively being analysed. 
503 The correlation between SHRIMP $\mathrm{H}_{2} \mathrm{O}$ determinations and the manometry with only a single

504 calibration is quite encouraging.

505

506 Although the measured ${ }^{16} \mathrm{O}^{1} \mathrm{H}^{-} /{ }^{16} \mathrm{O}^{-}$are consistent during the successive analyses of a single grain,

507 repeated analyses of the same sample but at different times (hours to days apart; within and between

508 different analytical sessions) give varied values for both the Cameca ims-6f and the SHRIMP SI (e.g.,

509 Supplementary file A2). As discussed above, this is likely to be due to a direct artefact of insufficient

510 pump down and vacuum equilibration prior to analysis. Other possible reasons for this variation

511 include localised charging related to the voltage on the electron gun and/or slight changes in the local

512 magnetic field. The different measured ${ }^{16} \mathrm{O}^{1} \mathrm{H}^{-} /{ }^{16} \mathrm{O}^{-}$ratios from different analytical times can lead to

513 greater errors on the subsequent calibration curves to calculate water contents. The variation on the

514 mineral analyses in the worse case example can lead to approx. $20 \%$ error, and therefore the difference

515 between the calibration curves of glass and NAM may lie within this $20 \%$ error. These errors can,

516 however, be mitigated by accurately determining the background $\mathrm{OH}^{-}$. This can be achieved by

517 analysing regularly throughout the session a sample that has little to no water content and subtracting

518 that value from the unknown analyses. Systematic errors to the calibration curve associated with drift

519 (other than background variations) can then be minimised by running standards at the beginning and

520 end of any analytical session and that each mount of unknown samples include at least three standards

521 relevant for the intended study. For example for NAM analyses, one that contains a relatively high

522 water content (e.g., KBH cpx or the Pakistani olivine), one that has a moderate water content (e.g.,

523 Russian Cr-diopside) and one with no or little water (e.g. the anhydrous Suprasil 3002).

524

525 Matrix Effects

526

527 Mineral matrix effects are a common phenomenon in ion microprobe analysis and have been apparent

528 almost since the inception of ion microprobe analysis of geological materials. ${ }^{30,42,43}$ A matrix effect

529 manifests itself as an ion ratio (atomic or molecular) that differs from the expectation based on

530 concentration differences, or isotope ratio differences, in different mineralogical phases. There appears

531 to be some systematic behaviour in these matrix effects that has been used to try and model the 
532 sputtering process, but the more common approach is to use mineral standards that are closely matched

533 in composition to the unknowns to allow empirical correction through fitting of calibration lines.

534

535 As such, we expect to see mineralogical control of the ionisation yields of $\mathrm{OH}^{-}, \mathrm{O}^{-}$and $\mathrm{Si}^{-}$used for 536 SIMS calibration. Interestingly, the ${ }^{16} \mathrm{O}^{1} \mathrm{H}^{-} /{ }^{16} \mathrm{O}^{-} \mathrm{vs}^{16} \mathrm{O}^{1} \mathrm{H}^{-} \beta^{30} \mathrm{Si}^{-}$data from SHRIMP and Cameca are 537 well fitted to a single line. This is not to suggest that there are no matrix effects, but rather the matrix 538 effects between these species are well correlated, and that there is little difference between the 539 sputtering, extraction, and instrumentally induced secondary ion fractionations between the two 540 instruments.

542 Of greater importance in our assessment of these standard materials is whether matrix effects between 543 SIMS and FTIR are of consequence. Unfortunately due to the limited dataset of mineral phases, their 544 major element compositions, and water concentrations, it is difficult to conclusively determine whether 545 matrix effects result in significant errors on our mineral calibration line for water concentration. As 546 noted above, a free fit to the data allows the determination of a slope (effectively the calibration 547 coefficient), and an intercept (for the SHRIMP data this is related to the background). For all SHRIMP $548{ }^{16} \mathrm{O}^{1} \mathrm{H}^{-} /{ }^{16} \mathrm{O}^{-}$data and the FTIR glass compositions ( $\left(\mathrm{t} t \% \mathrm{H}_{2} \mathrm{O}\right)$, there is a range from 1.1 to $2.0 \times 10^{-7}$, 549 with intercepts ranging from 3 to $5 \times 10^{-5}$ for the orthopyroxene, clinopyroxene and olivine, up to $3.5 \mathrm{x}$ $55010^{-4}$ for the glasses. Thus, while good correlations exist between ${ }^{16} \mathrm{O}^{1} \mathrm{H}^{-} /{ }^{16} \mathrm{O}^{-}$and $w t^{6} \mathrm{H}_{2} \mathrm{O}$, there is 551 insufficient data to clearly resolve ambiguities in sample water compositions, from any matrix552 controlled sputtering behaviour.

553

554 Several FTIR studies have shown that $\mathrm{OH}^{-}$or $\mathrm{H}_{2} \mathrm{O}$ can be incorporated within several sites of the 555 mineral structure. ${ }^{44,38}$, The unknown geometry and charge imbalances associated with the incorporation 556 of water within the mineral structure mean that the $\mathrm{OH}-$ bond strengths are also unknown and may be 557 unique to the composition of the mineral. ${ }^{23,10,11,39}$ The FTIR absorption coefficients found for a single 558 mineral composition will not be applicable to other minerals of different elemental composition. In 559 addition, differences in OH-bond strengths associated with different mineral compositions mean that 560 there will be differences in the ionisation of the $\mathrm{OH}^{-}$during analysis on the ion-microprobe, potentially 561 complicating the FTIR ion-probe calibration lines. 
563 Mosenfelder and Rossman ${ }^{10,11}$ recently discussed possible matrix effects of orthopyroxene and 564 clinopyroxene and compared them to analyses of olivine. Mosenfelder and Rossman ${ }^{10,11}$ show that any 565 matrix effect is likely to be less than $20 \%$, depending on which absorption coefficient is used for the 566 FTIR water determination. This is close to the level of water variability we see in the samples through 567 variations in all SIMS analysis, and cross referenced to FTIR analysis. At this stage, it would appear 568 that separate standardisation schemes for olivine, orthopyroxene, and clinopyroxene may be 569 unwarranted, and could in fact be detrimental if insufficient numbers of standard materials are 570 available with an appropriate range of water concentration.

571

572

\section{$\mathrm{OH}^{-}$background limitations}

573

574 The ${ }^{16} \mathrm{O}^{1} \mathrm{H}^{-}$background measured in SIMS instruments is related to residual $\mathrm{H}_{2} \mathrm{O}$ in the vacuum, 575 absorbing onto and desorbing from the sample surface, and specifically the sputter site where surface 576 water can then be sputtered by the $\mathrm{Cs}^{+}$primary beam and contribute to the secondary ion beam. 577 Another potential source of the SHRIMP SI $\mathrm{OH}^{-}$background may be related to ionization of $\mathrm{OH}^{-}$at 578 the target by electron impact, induced by the electron beam used for charge compensation arriving at 579 the surface at $1.5 \mathrm{keV}$. This is similar to the EISIE effect for oxygen ionisation noted in SHRIMP II. ${ }^{31}$ 580 However, the $\mathrm{OH}^{-}$production was checked when the Cs gun was turned off and there was no $\mathrm{OH}^{-}$ 581 emission above detector background.

582

583 In pumping down from atmospheric levels with an unbaked vacuum chamber, water is the main 584 contributor to the residual vacuum at levels down to $10^{-9}$ mbar. ${ }^{45}$ Water is a particularly difficult 585 vacuum residual species because of its propensity to stick to surfaces and hence baking is commonly 586 used to excite water from surfaces. However, regularly taking an ion microprobe source chamber to 587 temperatures in excess of $100{ }^{\circ} \mathrm{C}$ can be risky with a complicated set up of components that are not 588 necessarily designed for differential movement induced by thermal expansion. 589

590 Further improvements to the vacuum system that might directly affect ${ }^{16} \mathrm{O}^{1} \mathrm{H}^{-}$analysis are envisaged 591 for SHRIMP SI. The ion pump on the source chamber was installed to minimise vibration on the 
592 sample stage. While ion pumps have excellent ultimate vacuum characteristics, they are not the most

593 effective when a gas load is present. The best method for pumping residual water is through a

594 cryogenic pump and we envisage replacing the ion pump with a cryo-pump with appropriate

595 mechanical isolation to minimise vibration. It is expected that this will improve the ultimate vacuum

596 pressure in the source chamber, but will also allow us to get to ultimate background faster after analysis

597 of epoxy mounts.

598

599 The ultimate water background achieved for SHRIMP SI with the ion pump is around $30 \mathrm{ppm}$ (after 600 several days of pumping down in the sample chamber). This background can be quantified and 601 therefore removed by analysing suitable anhydrous materials (such as Suprasil glass) and the correction 602 will be appropriate provided the samples have equilibrated to the vacuum conditions.

603

604 Reference Materials

605

606

\section{GLASS STANDARDS}

607

608 The glasses used here were chosen because they are all of similar major element composition (Table 1) 609 and have water contents determined by FTIR and SIMS ranging from 0.39 to $1.56 \mathrm{wt} \%$. These criteria 610 are essential to create a calibration line that has a slope that is not compromised by a limited range of 611 water contents or significantly different matrix compositions. In addition, because the water content of 612 the most water-rich glass is just below $1.5 \mathrm{wt} \%$ compositionally related matrix effects (if any) are 613 limited. ${ }^{6}$

614

615 The structure of the $\mathrm{H}_{2} \mathrm{O}$ data from both the Cameca ims-6f and SHRIMP SI are very similar compared 616 to the conventional manometry-FTIR determinations (Fig. 5(a), Fig. 7(a)). Variation of analyses from 617 each glass shard are minimal $(<5 \%)$ from both the SHRIMP SI and the Cameca 6 f showing both that 618 the samples are homogenous to this level and that the reproducibility of both instruments is very good 619 for sub weight percent to weight percent water contents.

620 
621 The background extrapolated from the linear correlation in the glass data is quite high suggesting that 622 the SHRIMP analyses have a high background water level of order of 100-200 ppm. However, the 623 intercept of the line-fit is strongly controlled by the lowest analysis (Glass 24.1). The SHRIMP 624 analysis indicates a higher ${ }^{16} \mathrm{O}^{1} \mathrm{H}^{-} /{ }^{16} \mathrm{O}^{-}$than the corresponding Cameca ${ }^{16} \mathrm{O}^{1} \mathrm{H}^{-} \rho^{30} \mathrm{Si}^{-}$measurement for 625 this glass. As noted above, there is a notable difference between the Cameca water concentration 626 (3900 ppm) and the FTIR determination mean (3100 ppm). It is likely that this glass might be slightly 627 more heterogeneous than other glasses and its use on the calibration line may create excess variability 628 where it can cause a significant change in the intercept of the calibration line. The calibration is lacking 629 a suitable glass with very low water content to better constrain the line fit if only glasses are to be used. 630

631 Caulfield et al. ${ }^{16}$ used the CIW Cameca of SIMS and the ANU FTIR instrument to analyse water 632 within the glass shards used to aid their U-Th-Ra model of fluid-flux melting at the Fonualei Spreading 633 Center and Valu Fa Ridge, Tonga. Similar to our findings here, they found that there was a good 634 agreement between the FTIR and SIMS determined water concentrations. ${ }^{16}$ However, FTIR and 635 Cameca ims-6f determined water contents of ND61 and ND69 presented in Table 2 are 12-15 wt\% 636 higher than those found by both the Caulfield et al. ${ }^{16}$ study, as well as those presented in Lloyd et al. ${ }^{17}$ 637 The multiple analyses of individual glass shards by various instruments indicate that individual glass 638 shards are homogenous (Table 2). Therefore, the discrepancy between the water contents found in the 639 glass samples from our study compared to both Caulfield et al. ${ }^{16}$ Lloyd et al. ${ }^{17}$ reflects true differences 640 in water concentrations between glass shards from the large sample batch.

641

642 2. NOMINALLY ANHYDROUS MINERALS

643

644 Major element compositions for many of the nominally anhydrous minerals are similar to those in 645 previously published studies on these minerals (PMR-53 cpx, KBH-opx ${ }^{13}$; KBH-cpx ${ }^{1}$; Rus Cr-diop $646{ }^{19,20}$; Tan-opx ${ }^{25}$ ). The exception being the Pakistani olivine sample that has approximately $4 \mathrm{wt} \%$ more $647 \mathrm{MgO}$ and $\mathrm{FeO}^{\mathrm{t}}$ (Table 1) than the grain analyses in the Gose et al. ${ }^{22}$ study. These differences are likely 648 to result from variations in the amount of serpentinsation of individual olivine grains within individual 649 veins of the dunitic rock. 
651 The background vacuum water contribution to SHRIMP SI ${ }^{16} \mathrm{O}^{1} \mathrm{H}^{-} /{ }^{16} \mathrm{O}^{-}$determinations is clearly an 652 issue for samples with less than $100 \mathrm{ppm} \mathrm{H}_{2} \mathrm{O}$. For SHRIMP SI calibrations below this concentration 653 level, a secondary standard such as San Carlos olivine will allow confirmation that the samples have 654 equilibrated in the vacuum system and that Suprasil glass allows an appropriate background correction. 655

656 Mineral matrix effects in ion-probe analysis, associated with differences in intra and interphase 657 compositions, is likely to be an important control in the mineral specific water calibration lines. 658 However at this stage the perturbations caused by matrix effects are possibly at a similar level to the 659 heterogeneity in the samples used for calibration. Mosenfelder and Rossman ${ }^{10,11}$ recently discussed 660 the possible matrix effects of orthopyroxene and clinopyroxene and compared them to the analyses of 661 olivine. Mosenfelder and Rossman ${ }^{10,11}$ show that matrix effect is less than $20 \%$, depending on which 662 absorption coefficient is used for the FTIR water determination. This is of a similar magnitude to the 663 dispersion around the best-fit lines for SIMS data versus manometry-FTIR (Fig. 5, 7). With a limited 664 number of standard materials, finding systematic differences in terms of apparent water content that 665 can be interpreted as matrix effects as opposed to real variation in the targets is difficult.

666

\section{POSSIBLE NAM STANDARDS FOR WATER DETERMINATION BY FTIR AND SIMS}

668

669 To acquire calibration lines for analysing water in NAMs by the SHRIMP SI (or any SIMS instrument) 670 a set of mineral standards with a range of $10-500 \mathrm{ppm}$ water concentrations must be characterized, and 671 be homogenous in regards to water concentrations. We have therefore concentrated on analysing 672 minerals that have $\mathrm{H}_{2} \mathrm{O}$ measurements from vacuum extraction manometry (e.g. KBH-1 opx, PMR-53 $673 \mathrm{cpx})^{13}$ and have also begun to look at pyroxene and olivine inclusion free gemstones that have the 674 potential to be future standards for water analyses.

675

676 Pakistani olivine has a hydrothermal origin, and therefore there are some grains that contain inclusions 677 that will need to be avoided if it is to be used as a standard. ${ }^{22,23,24}$ Additionally, there is a huge grain-to678 grain variation in water contents. In this study we examined an exceptionally water-rich sample that 679 has about $340 \mathrm{ppm} \mathrm{H}_{2} \mathrm{O}$, whereas the sample investigated by Kovács et al. ${ }^{23}$ only contained $72 \mathrm{ppm}$ 680 $\mathrm{H}_{2} \mathrm{O}$. It is thus essential that each Pakistani Olivine grain used for SIMS measurements is first analysed 
681 by FTIR and water contents should be quantified using the absorption coefficient of $0.57 \pm 0.04$ from

682 Kovács et al. ${ }^{23}$

683

684 PMR-53 cpx, KBH cpx and KBH-1 opx are currently being used (along with ROM-XXX samples from 685 the study of Bell et al. ${ }^{46}$ ) as pyroxene standards by several SIMS and FTIR laboratories worldwide. 686 While there can be considerable differences in the $\mathrm{OH}^{-}$from different sessions and different 687 instruments, consistent correlations of these samples from each analytical session suggest that there is 688 no significant heterogeneity among the different standards used by the different laboratories. Therefore 689 PMR-53 cpx, KBH cpx and KBH-1 opx should be used for SIMS and FTIR standards for water 690 determinations of pyroxene. Mosenfelder and Rossman, ${ }^{11}$ however, do point out that standard PMR-53 691 cpx is a 'problem sample' because it plots at too low $\mathrm{H}$ content and/or too high SIMS ${ }^{16} \mathrm{O}^{1} \mathrm{H}^{-}{ }^{\beta 0} \mathrm{Si}^{-}$ 692 ratios compared to the other clinopyroxene samples (e.g. Fig. 5). While this observation is disturbing, 693 because the PMR-53 cpx has been studied by multiple techniques and was used by Bell et al. ${ }^{13}$ to 694 determine the FTIR absorption coefficients for clinopyroxene, there is no satisfactory answer to why it 695 plots so far off SIMS calibration lines ${ }^{11}$ and until this issue is resolved, we suggest PMR-53 cpx is not 696 used as a standard for FTIR or SIMS clinopyroxene water studies.

697

698 Aubaud et al. ${ }^{26}$ indicate that their studied grain of San Carlos olivine has water contents generally less 699 than $1 \mathrm{ppm}$. We have investigated a large number (> 25) of mm-sized San Carlos olivine cubes with IR 700 spectroscopy and most samples have water contents at or below the detection limit of about $1 \mathrm{ppm}$. 701 However, the FTIR analysis of the San Carlos olivine-2 grain presented here shows that some grains 702 can have approximately 10 ppm $\mathrm{H}_{2} \mathrm{O}$ (Fig. 3, Table 3). Also Li et al. ${ }^{27}$ reported San Carlos olivine 703 with 2-4 ppm $\mathrm{H}_{2} \mathrm{O}$. Similar findings have been found for some major and trace elements within 704 different sized grains of San Carlos olivine. ${ }^{47}$ The heterogeneity of $\mathrm{OH}^{-}$between different San Carlos 705 olivine grains of different sizes suggests that it too should only be used as a reliable standard for low 706 water concentrations if it is first characterised by FTIR measurements.

707

708 The Russian Cr-diopside and Tanzanian orthopyroxene also appear to have minimal variation in 709 respect to major element and water concentrations within single grains during a single analytical 710 session (Supplementary file A2). This agrees well with recent FTIR studies of Moesenfelder and 
711 Rossman ${ }^{10,11}$ and we conclude that these two readily available gemstones, that are generally free of 712 inclusions and contain homogenous water contents, might be suitable as standards for water analyses.

713 If the water contents of these minerals can be determined independently by an absolute method (i.e., 714 manometry), these NAMs are therefore ideal candidates for international laboratory standards.

715

716

Conclusions

717

718 The SHRIMP SI has been used to measure water concentrations for the first time in a series of 719 reference materials. The data have been compared with measurements of the same mounts on the Cameca ims-6f at CIW, and with FTIR measurements on fragments of the same materials at ANU. SHRIMP SI analysis of NAMs with less than $100 \mathrm{ppm}$ water is somewhat problematical because of the water background contributed by the vacuum $(\approx 30 \mathrm{ppm})$, and the variable retention of water on the surfaces of mineral grains. The background can be monitored by analyses of Suprasil glass in conjunction with San Carlos olivine as a secondary near water-free standard. Despite the background issues for NAMs, the SHRIMP data are well correlated to Cameca ims-6f data and FTIR data and SHRIMP SI appears capable of determining water concentrations in volcanic glasses at 500 to 15,000 ppm levels in its current configuration.

728

729 A set of natural and/or synthetic NAMs standards need to be developed and used as inter-laboratory standards for both FTIR and ion-probe studies. These standards need to be both homogenous in

731 composition and water contents. Ideally, during each SIMS analytical session three matrix-matched standards (one blank, and two variable water contents) should be run periodically. The samples used by

733 Bell et al. ${ }^{13}$ and Rossman and Bell ${ }^{1}$ along with the samples of Bell et al. ${ }^{46}$ (not studied here) should be 734 used as inter-laboratory standards for water analyses of NAM. In addition once the absolute water 735 concentration of the Russian Cr-diopside and the Tanzanian orthopyroxene are made, then these 736 samples could also be used as FTIR and SIMS NAM standards for water determination.

737 738 Acknowledgements 739 
740 We would like to thank David Bell for providing fragments of samples used in the Bell and Rossman 741 (1992) and Bell et al. (1995) studies. Richard Arculus provided glass samples from the Fonualei 742 Spreading Centre and Mangatolo Triple Junction and John Sinton provided glass samples from the 743 Manus back-arc basin. We would also like to thank David Kohlstedt for donating fragments of San 744 Carlos olivine. Mark Hirschmann provided useful advice on analysing water in NAMs by ion745 microprobe. S.T. was supported by an Australian Research Council Professorial Fellowship 746 (DP0988658) and M.T. by a New Zealand Foundation for Research, Science and Technology post747 doctoral Fellowship. J. A. P-N has been additionally funded by HISLa-DR, Marie Curie Action under 748 grant agreement PIOF-GA-2010-273017 from the European Union Seventh Framework Programme 749 (FP7/2007-2013). This work was supported by ARC DP140100622 to Hermann and Ireland.

750

751

752 Notes and References:

753

$754 \quad{ }^{\mathrm{a}}$ Department of Earth and Planetary Sciences, Macquarie University, NSW, Australia

$755{ }^{\mathrm{b}}$ Research School of Earth Sciences, Australian National University, ACT, Australia

$756{ }^{\mathrm{c}}$ Géosciences Montpellier, University of Montpellier \& CNRS, Place E. Bataillon 34095 Montpellier 757 cedex 5, France

$758{ }^{\mathrm{d} C}$ Carnegie Institution of Washington, 5424 Broad Branch Road, Washington, D.C. 20005, USA

759

$760 \quad$ 1. D.R. Bell, G.R. Rossman, Science, 1992, 255, 1391-1397.

761 2. E. Stolper, S. Newman, Earth Planet. Sci. Lett., 1994, 121, 293-325.

762 3. A.V. Sobolev, M. Chaussidon, Earth Planet. Sci. Lett., 1996, 137, 45-55.

763 4. J. Blundy, K.V. Cashman, Geology, 2005, 33, 793-796.

764 5. T. Plank, K.A. Kelley, M.M. Zimmer E.H. Hauri, P.J. Wallace, Earth Planet. Sci. Lett.,. 2013, $765 \quad 364,168-179$.

766 6. E.H. Hauri, J. Wang, J.E. Dixon, P.L. King, C. Mandeville, S. Newman, Chem. Geol., 2002, $767 \quad \mathbf{1 8 3}, 99-114$.

768 7. K. Koga, E.H. Hauri, M.M. Hirschmann, D.R. Bell, Geochem. Geophys. Geosys., 2003, 4.2 1019. Doi:10.1029/2002GC000378. 
770 8. E.H. Hauri, G.A. Gaetani, T.H. Green, Earth Planet. Sci. Lett., 2006, 248, 715-734 doi: $771 \quad$ 10.1016/j.eps1.2006.06.014.

$7729 . \quad$ J. Wade, T. Plank, .M. Zimmer, E.H. Hauri, K. Roggensack, K. Kelley, Geology, 2008, 36, 773 $799-802$.

774 10. J.L. Mosenfelder G.R. Rossman, Am. Mineral., 2013a, 98, 026-1041 doi:10.2138/am.2013.4291

776 11. J.L. Mosenfelder G.R. Rossman, Am. Mineral., 2013b, 98, 1042-1054 777 doi:10.2138/am.2013.4413

778 12. E. Libolwitzky, G.R. Rossman, Phys. Chem. Minerals., 1996, 23, 319-327.

779 13. D.R. Bell, P.D. Ihinger, G.R. Rossman, Am. Mineral,, 1995, 80, 465-474.

780 14. N.S. Keller, R.J. Arculus, J. Hermann, S. Richards, J. Geophys. Res. Solid Earth, 2008,113 $781 \quad$ B08S07.

782 15. J.M. Sinton, L.L. Ford, B. Chappell, M.T. McCulloch, J. Petrol., 2003, 44, 159-195.

783 16. J. Caulfield, S. Turner, R. Arculus, C. Dale, F. Jenner, J. Pearce, C. Macpherson, H. Handley, 784 J. Geophys Res., 2012, 177, B11209 doi:10.1029/2012JB009526.

785 17. A.S. Lloyd, T. Plank, P. Ruprecht, E.H. Hauri, W. Rose, Contrib. Mineral. Petrol., 2013, 165, $786 \quad 129-153$.

787 18. R.D. Shannon, J.E. Dickinson, G.R. Rossman, Phys. Chem. Minerals, 1992, 19, 148-156.

788 19. J. Ingrin, N. Doukhan, J.C. Doukhan, J. Geophys. Res. Solid Earth, 1991, 96(B9), $14287-$

789 14297 doi:10.1029/91JB01233

790 20. J. Ingrin, S. Hercule, T. Charton, J. Geophys. Res. Solid Earth, 1995, 100(B8), 15489-15499 791 doi:10.1029/95jb00754

792 21. J. Gose, P. Reichart, G. Dollinger E. Schmädicke, Am. Mineral. 2008, 93, 1613-1619.

793 22. J. Gose, E. Schmädicke, M. Markowitz, A. Beran, Mineral. Petrol., 2010, 99, 105-111.

794 23. J. Kovacs H. O'Neill J. Hermann E.H. Hauri Am. Mineral., 2010, 95, 292-299 795 doi:10.2138/am.2010.3313

796 24. P. Boulhol, J.P. Burg, J.L. Bodinier, M.W. Schmidt, S.M. Bernasconi, H. Dawood, Can. 797 Mineral., 2012, 50, 1291-1304.

798 25. A. Beran, J. Zemann, Tschermaks Mineralogische and Petrographische Mitteilungen 1986, 35, 799 $19-25$. 
800 26. C. Aubaud, A.C. Withers, M.M. Hirschmann, Y. Guan, L.A. Leshin, S.J. Mackwell, D.R. Bell, $801 \quad$ Am. Mineral., 2007, 92, 811-828.

802 27. Z-X.A. Li C-T.A. Lee A.H. Peslier A. Lenardic S.J. Mackwell J. Geophys. Res. Solid Earth, 803 2008, 113(B9), B09210 doi:10.1029/2007jb005540

804 28. T.R. Ireland, S. Clement, W. Compston, J.J. Foster, P. Holden, B. Jenkins, P. Lanc, N. Schram, 805 I.S. Williams, Australian J. Earth Sci., 2008, 55, 937-954.

806 29. H. Matsuda, Int. J. Mass Spectrom. Ion Phys., 1974, 14, 219-233.

807 30. T.R. Ireland, N. Schram, P. Holden, P. Lanc, J. Avila, R. Armstrong, Y. Amelin, A. Latimore, 808 D. Corrigan, S. Clement, J.J. Foster, W. Compston, Int. J. Mass Spectrometry 2014, 359, 26809 37.

810 31. R.B. Ickert, J. Hiess, I.S. Williams, P. Holden, T.R. Ireland, P. Lanc, N. Schram, J. 811 Foster, S.W. Clement Chem. Geol. 2008, 257, 114-128.

812 32. T.R. Ireland, Geochim. Cosmochim. Acta, 1988, 52, 2827-2839.

813 33. A.J. Fahey, J.N. Goswami, K.D. McKeegan, E. Zinner, Geochim. Cosmochim. Acta,1987, 51, $814 \quad 329-350$.

815 34. J.E. Dixon, E.M. Stopler, J.R. Halloway, J. Petrol., 1995, 36, 1607-1631.

$81635 . \quad$ P.D. Ihinger, R.L. Hervig, P.F. McMillan, Reviews in Mineralogy, 1994, 30, 67-121.

817 36. E. Stopler, Geochimica et Cosmochimica Acta, 1982, 46, 2609-2620.

818 37. C.W. Mandeville, J.D. Webster, M.J. Rutherford, B.E. Taylor, A. Timbal, K. Faure, Am. 819 Mineral. 2002, 87, 813-821

$820 \quad 38 . \quad$ A.J. Berry, H. O’Neill, J. Hermann, D.R. Scott, Earth. Planet. Sci. Lett., 2007, 261, 134-142.

821 39. J. Ingrin, I. Kovacs, E. Deloule, E. Balan, M. Blanchard, S.C. Kohn, J. Herman, Am. Mineral., $822 \quad 2014,99,2138-2142$.

823 40. D.R. Bell, G.R. Rossman, J. Maldener, D. Endisch, F. Rauch, J. Geophys. Res. Solid Earth, 2003 108(B2) doi:2105 Artn 2105.

825 41. K. Ludwig, Berkeley Geochronology Center Special Publication 2012 5,

826 42. N. Shimizu, S.R. Hart, Annual Review of Earth and Planetary Sciences, 1982 10, 483.

827 43. T.R. Ireland, in: Hyman, M., Rowe, M. (Eds.), Advances in Analytical Geochemistry. JAI Press, 828 Greenwich 1995, 1-118.

829 44. E. Libolwitzky, A.Beran, Phys. Chem. Mineral. 1995, 22, 387-392. 
45. D. Hoffman, B. Singh, J.H. Thomas III Handbook of Vacuum Science and Technology, 1998,

$831 \quad 835 \mathrm{pp}$.

832 46. D.R. Bell, G.R. Rossman, R.O. Moore, J. Petrol., 2004, 45, 1539-1564

833 47. J.H. Fournelle, Microsc. Microanal., 2011, 17, S2, 842-843.

834

835

836 Figure captions

837

838 Fig. 1. Schematic illustration of the SHRIMP SI at The Australian National University, Canberra, 839 Australia.

840

841 Fig. 2. ${ }^{17} \mathrm{O}$ and ${ }^{16} \mathrm{O}^{1} \mathrm{H}$ peak resolution of the SHRIMP SI. (a) Linear scale for counts per second and (b) $842 \log$ scale.

843

844 Fig. 3. FTIR absorption peaks of basaltic glasses used in this study, normalised to $1 \mathrm{~cm}$ sample 845 thickness.

846

847 Fig. 4. Uncorrected FTIR absorption spectra for olivines and pyroxenes measured in this study.

848 Baselines are shown with dashed lines (raw and corrected data can be found in the SupplementaryData 849 A1).

850

851 Fig. 5. $\mathrm{OH}^{-}$measurements from the Cameca ims-6f $\left({ }^{16} \mathrm{O}^{1} \mathrm{H}^{-} /{ }^{30} \mathrm{Si}^{-}\right)$compared to those obtained from 852 manometry and FTIR for basaltic glasses and NAMs. Error bars represent the spread in the data. (a) 853 scale to show all glass and NAMs data, (b) scale to highlight NAMs data. Best-fit lines are plotted for 854 an unweighted regression (thicker broken line), and a weighted-line fit (solid line with thinner broken 855 lines as the $95 \%$ confidence limit of the data). Weighted line fit from IsoPlot 3 (Ludwig ${ }^{41}$ ). The 856 unweighted line is not well fitted to the NAMs data but a weighted line fit is appropriate for the whole 857 data set with the correlation passing close to the origin and all data within $\approx 10 \%$ of the weighted line fit. $858 \mathrm{SCO}=$ San Carlos olivine.

859 
860 Fig. 6. $\mathrm{OH}^{-}$measurements from the SHRIMP SI $\left({ }^{16} \mathrm{O}^{1} \mathrm{H}^{-} /{ }^{16} \mathrm{O}^{-}\right)$compared to those obtained from the

861 Cameca ims-6f $\left({ }^{16} \mathrm{O}^{1} \mathrm{H}^{-}{ }^{30} \mathrm{Si}^{-}\right)$for glasses and NAMs. (a) Scale to show all glass and NAMs data, (b)

862 scale to highlight NAMs data. Best-fit lines are plotted for an unweighted regression (thicker broken

863 line), and a weighted-line fit (solid line with thinner broken lines as the $95 \%$ confidence limit of the

864 data). Weighted line fit from IsoPlot $3\left(\right.$ Ludwig $\left.^{41}\right) . \mathrm{SCO}=$ San Carlos olivine. The SHRIMP ${ }^{16} \mathrm{O}^{1} \mathrm{H}$

$865 \quad{ }^{16} \mathrm{O}^{-}$data are well correlated with the Cameca ${ }^{16} \mathrm{O}^{1} \mathrm{H}^{-}{ }^{30} \mathrm{Si}^{-}$and a satisfactory weighted line fit is

866 apparent. However, the SHRIMP data have an apparent background ${ }^{16} \mathrm{O}^{1} \mathrm{H}^{-} /{ }^{16} \mathrm{O}^{-}$level of $\approx 3 \times 10^{-5}$

867 which is due to the higher vacuum pressure in the SHRIMP SI source chamber compared to the

868 Cameca ims-6f chamber. At these pressure levels, the main species in the vacuum is water. San

869 Carlos olivine (SCO) is distinctly high in this data set; on extended pumping the ${ }^{16} \mathrm{O}^{1} \mathrm{H}^{-} /{ }^{16} \mathrm{O}^{-}$

870 background can be improved to a level $\leq 2 \times 10^{-5}$, similar to the value for Suprasil glass.

871

872 Fig. 7. SHRIMP $\mathrm{SI}_{2} \mathrm{O}$ concentrations in glasses and NAMs determined after background correction

873 and calibration to FTIR or vacuum extraction manometry measurements. The calibration is based on

874 the weighted line fit to all data. (a) Scaled to show all glass and NAMs data, (b) scaled to highlight

875 NAMs data.

876 


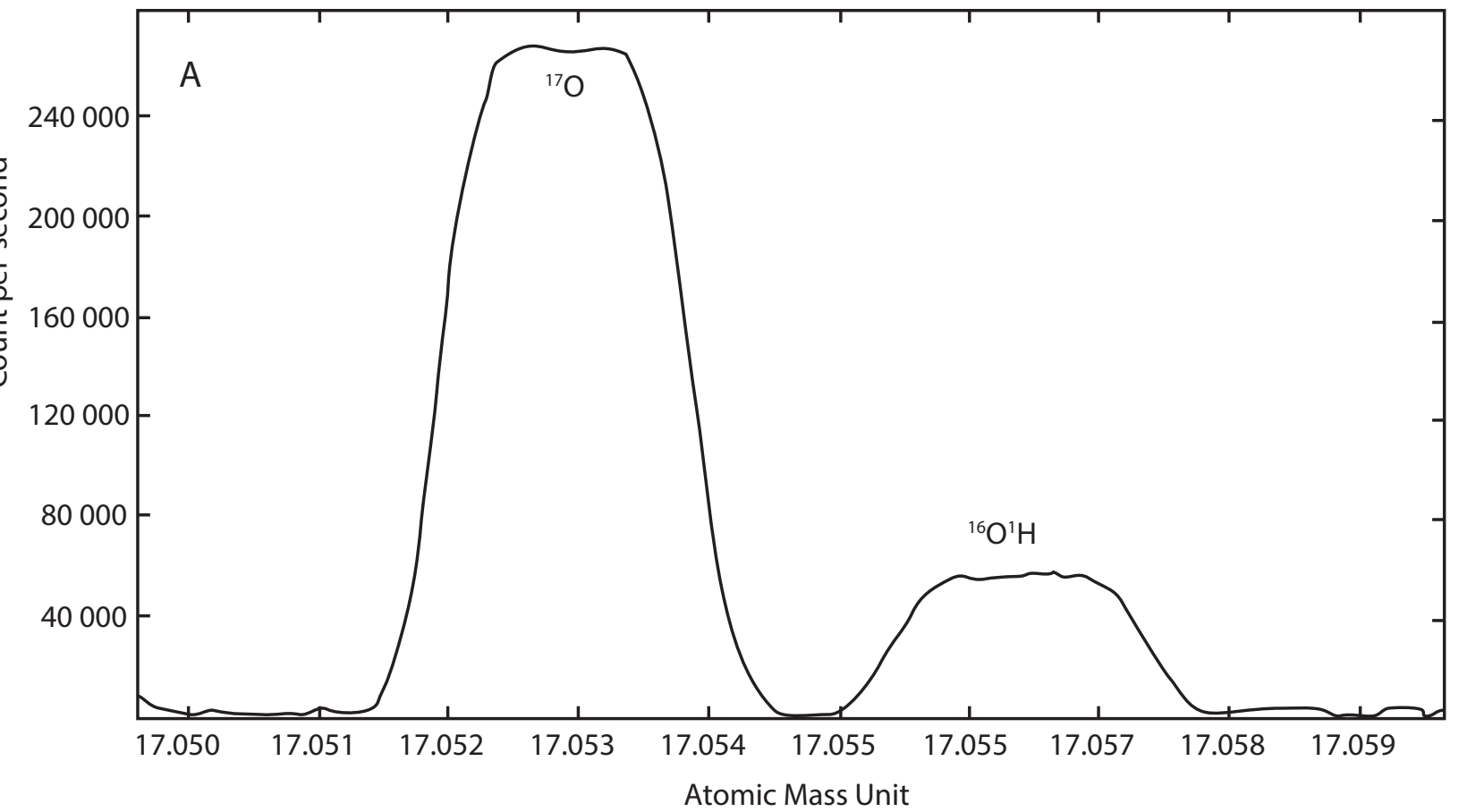

1000000 


\section{Page 33 of 49}

Journal of Analytical Atomic Spectrometry

Figure 3

1
2
3
4
5
6
7
8
9
10
11
12
13
14
15
16
17
18
19
20
21
22
23
24
25
26
27
28
29
30
31
32
33
34
35
36
37
38
39
40
41
42
43
44
45
46
47

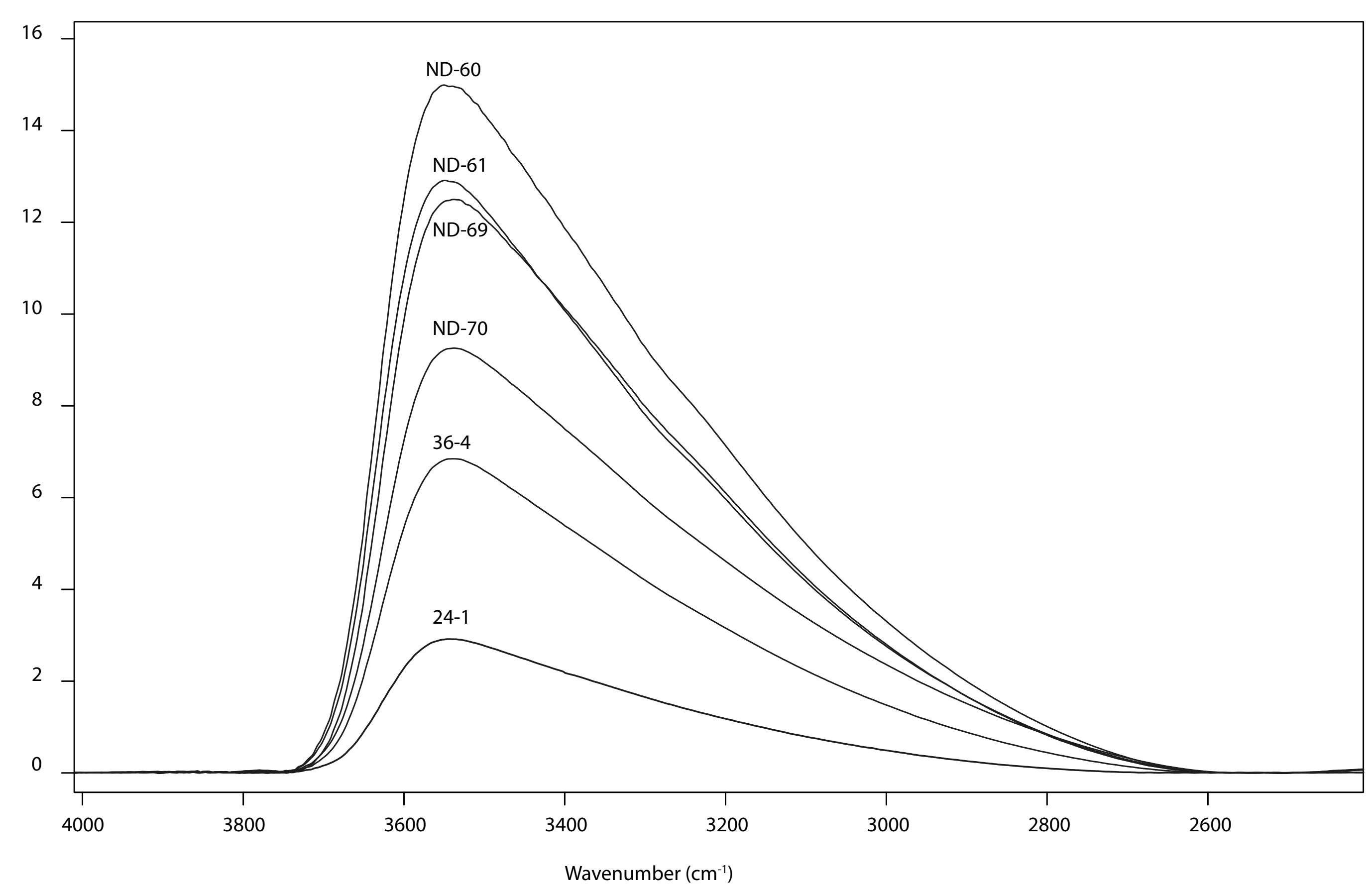



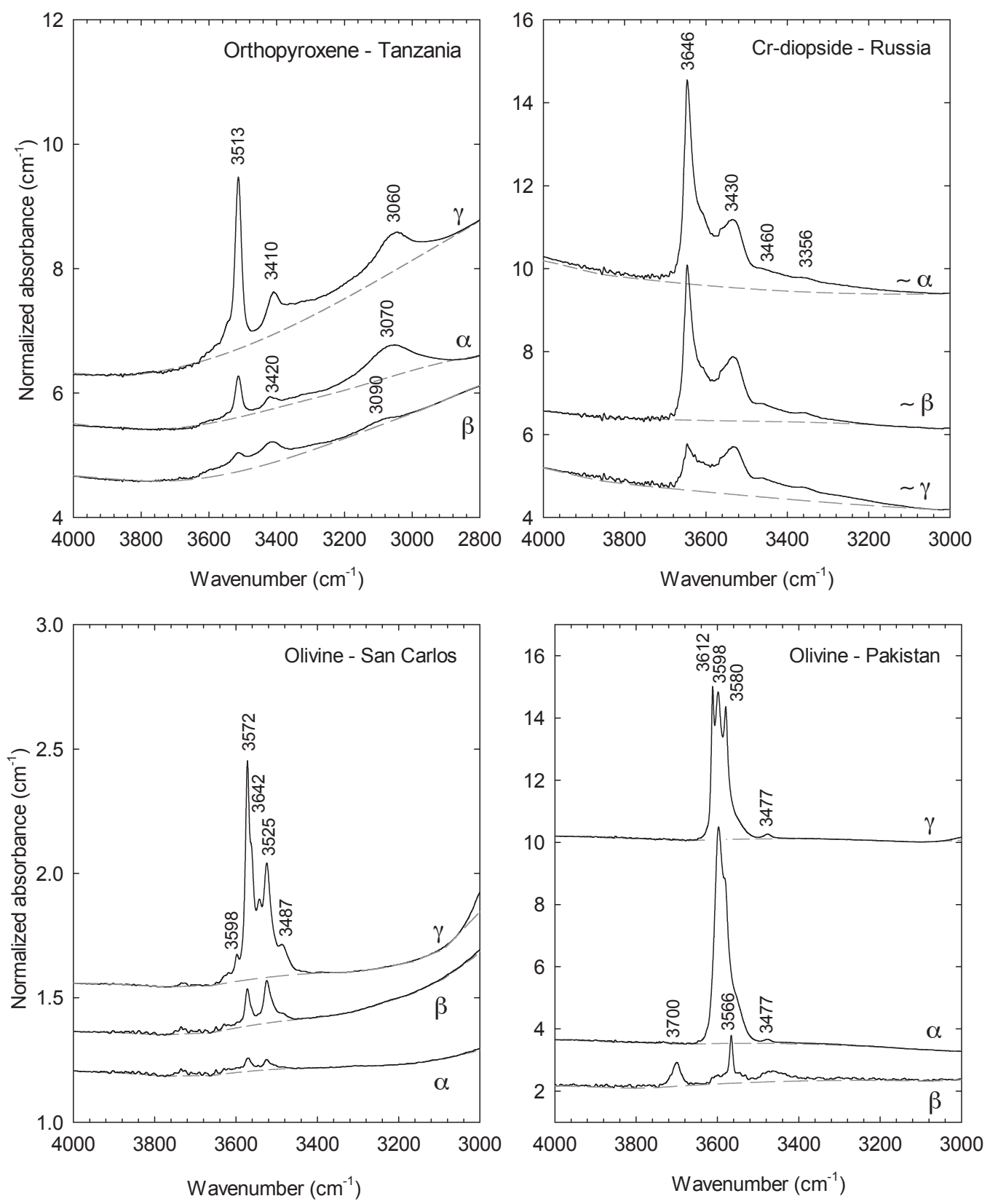
Figure 5(a)

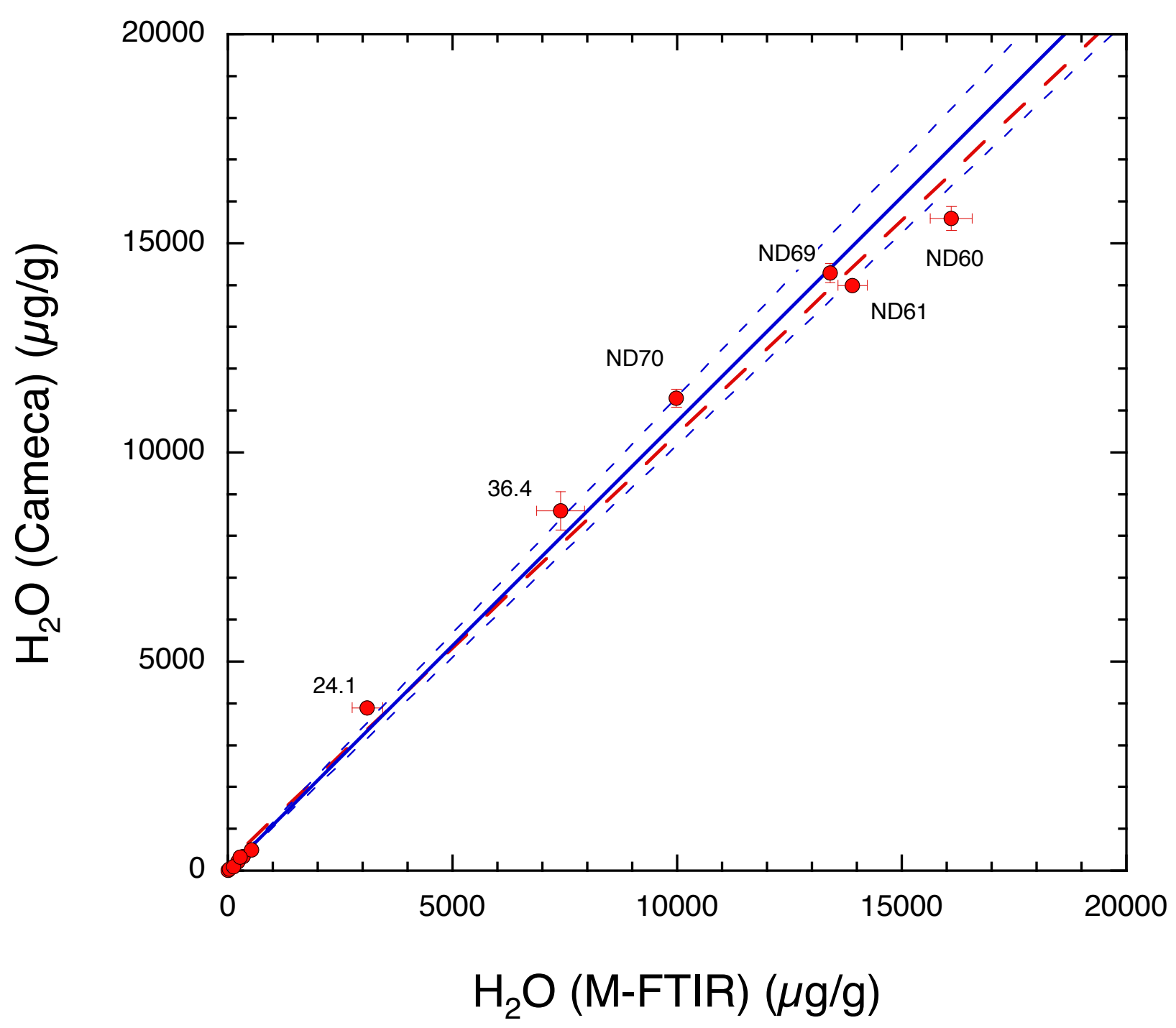


Figure 5(b)

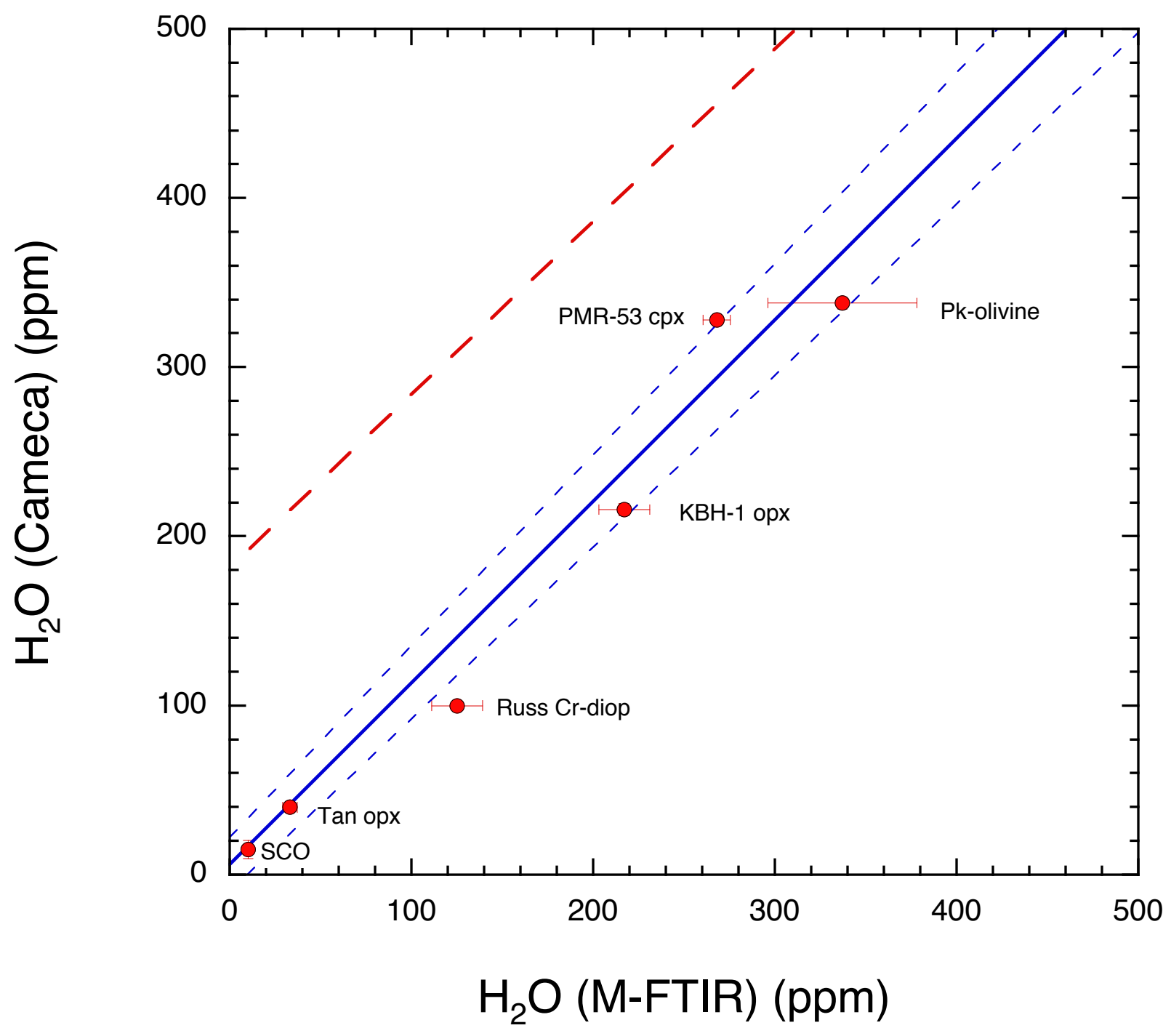


Figure 6(a)

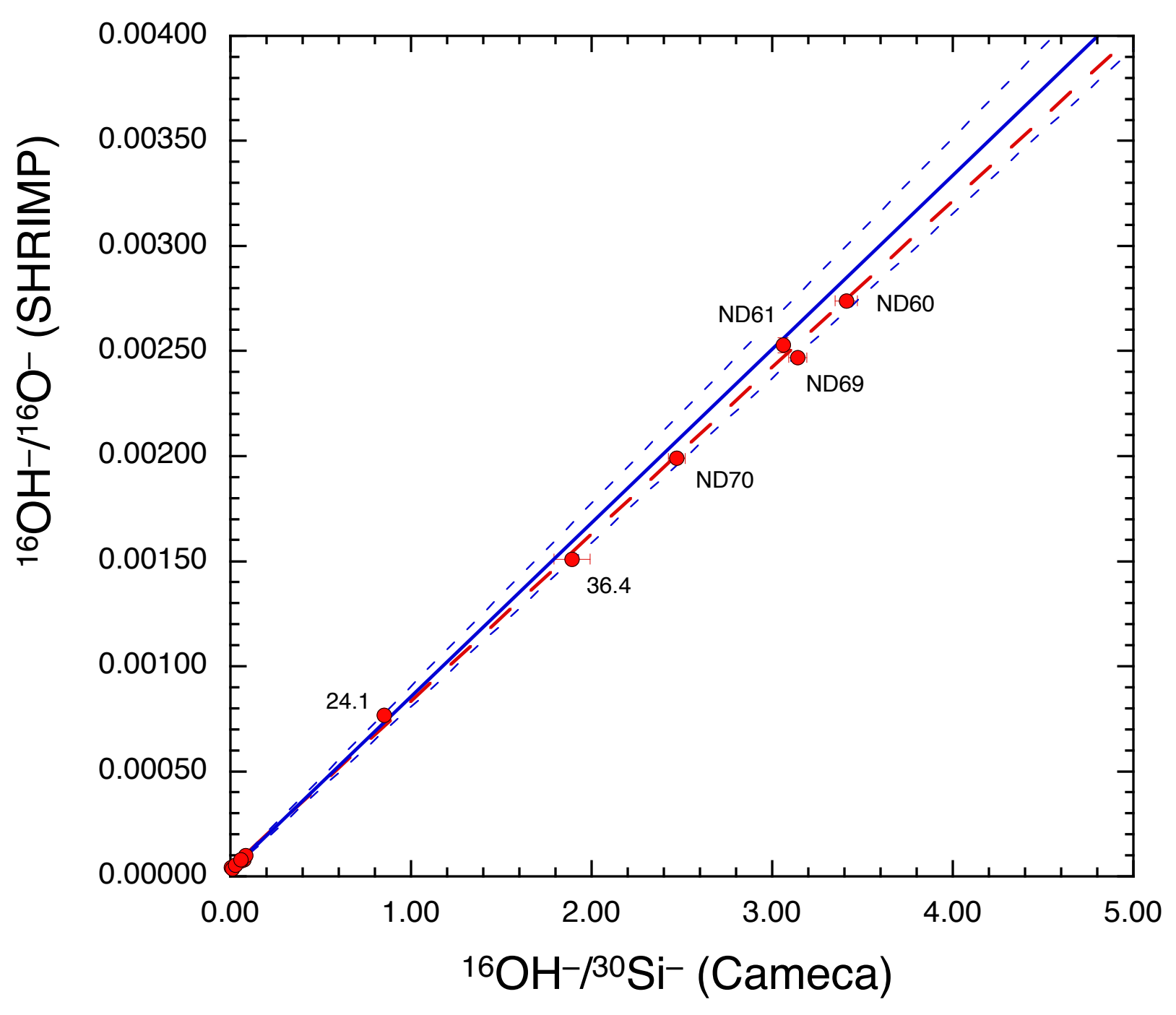


Figure $6 b$

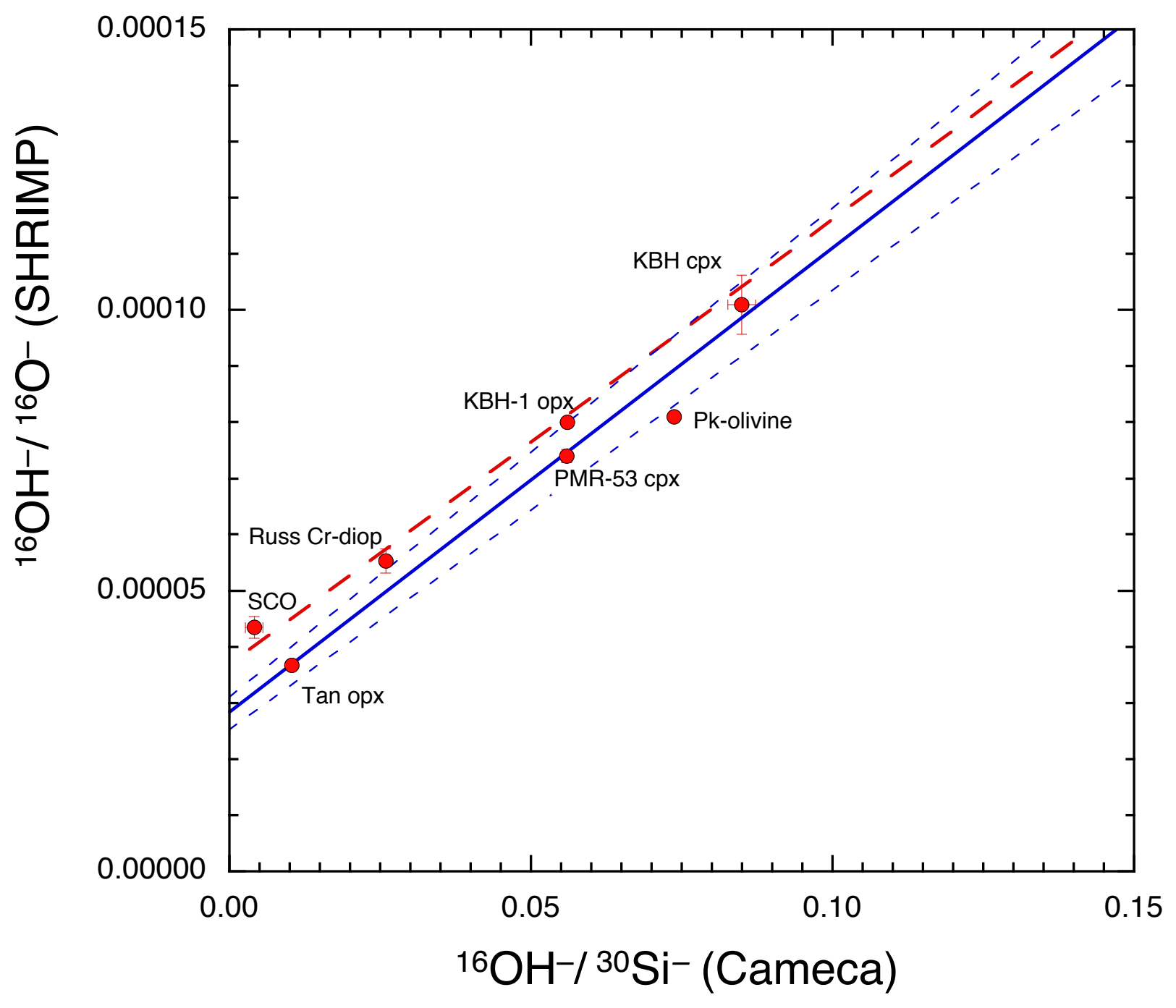


Figure $7 a$

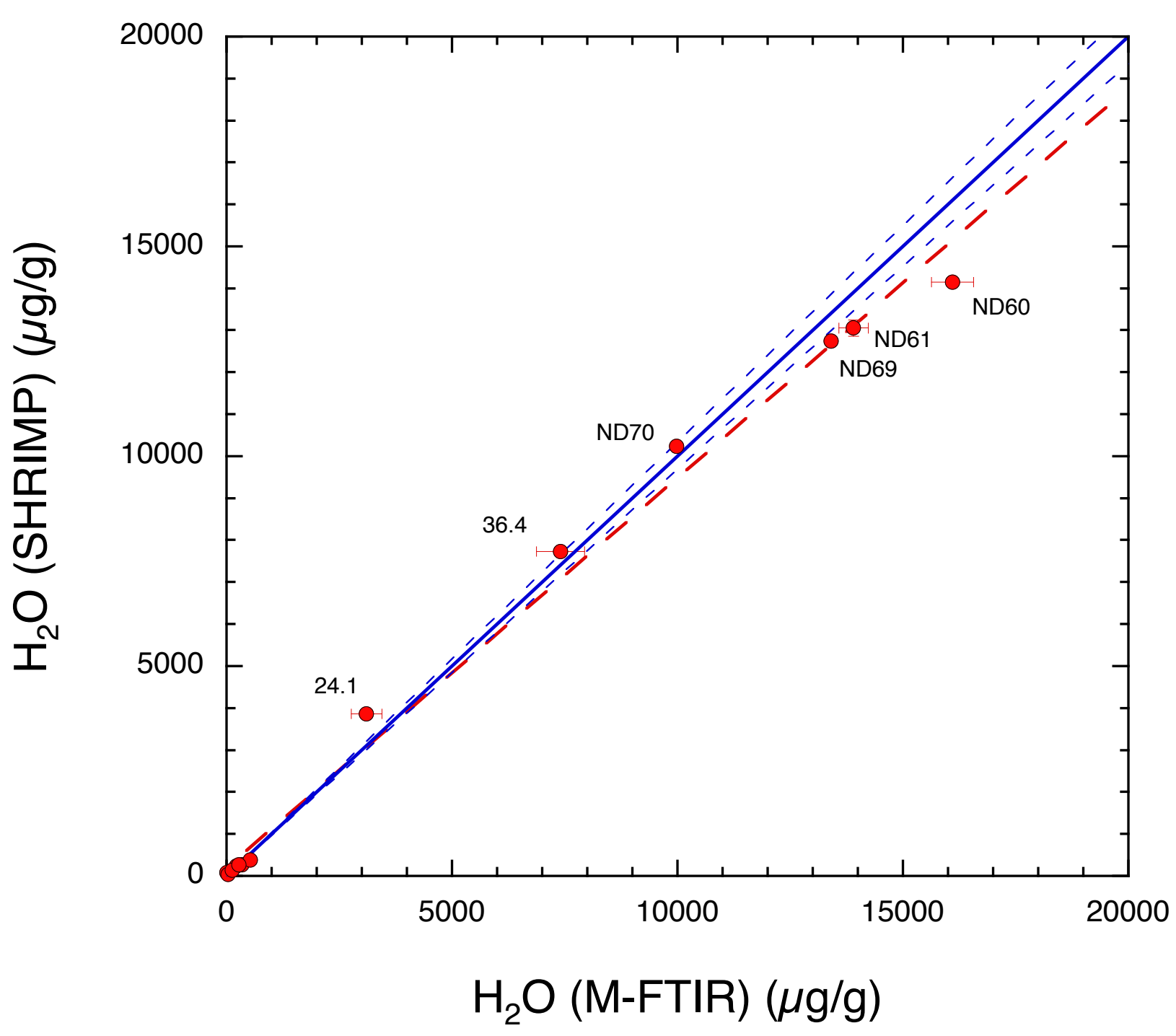


Figure $7 b$

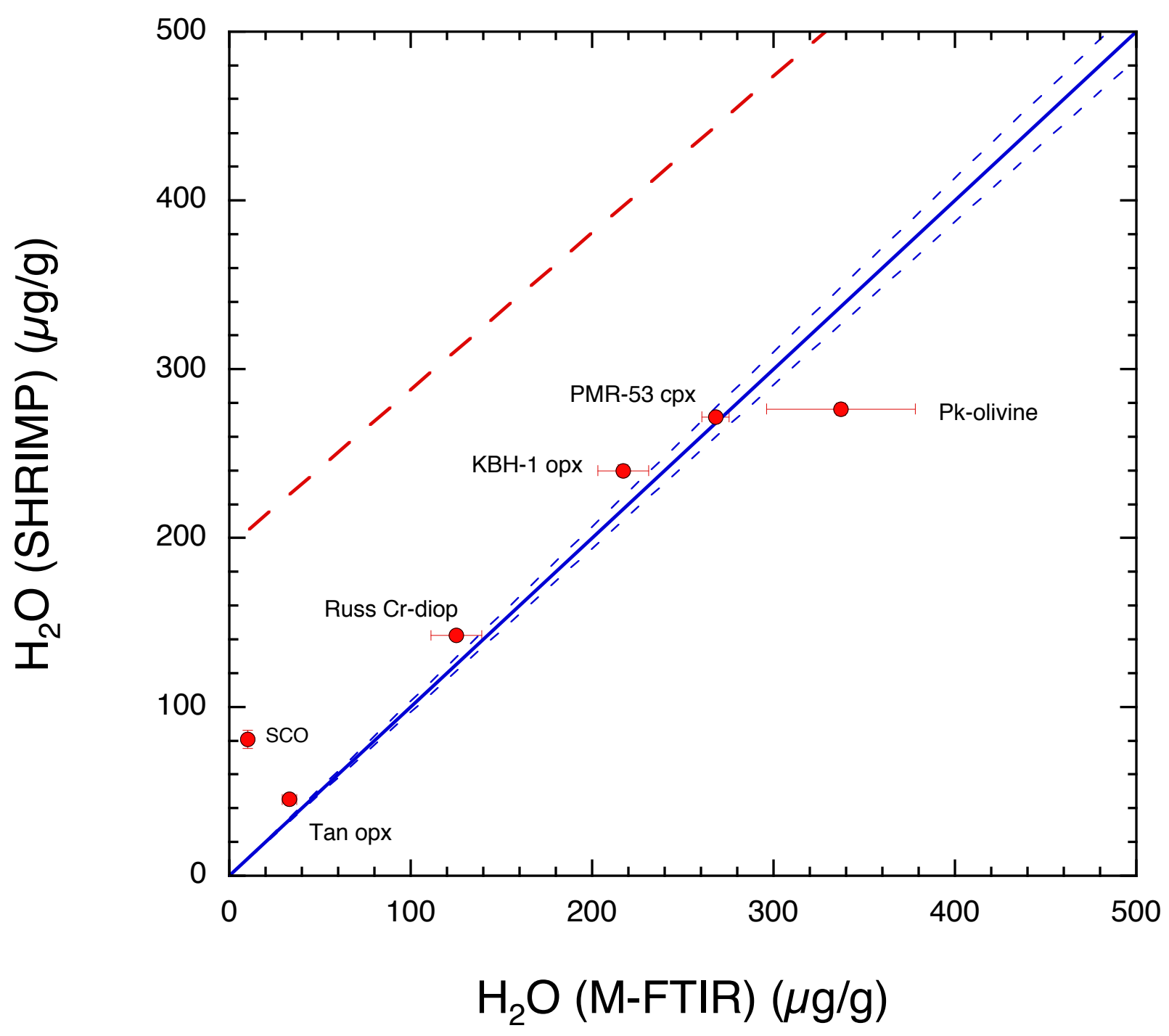


Table 1: Electron microprobe analyses of glass and mineral samples

\begin{tabular}{|c|c|c|c|c|c|c|}
\hline & $\mathrm{SiO}_{2}$ & $\mathrm{TiO}_{2}$ & $\mathrm{Al}_{2} \mathrm{O}_{3}$ & $\mathrm{Cr}_{2} \mathrm{O}_{3}$ & $\mathrm{FeO}^{\mathrm{t}}$ & $\mathrm{MnO}$ \\
\hline \multicolumn{7}{|l|}{ Glass } \\
\hline 36.4 & $50.84(0.5)$ & $2.06(0.9)$ & $13.24(0.8)$ & bdl & $13.89(0.6)$ & $0.24(8.5)$ \\
\hline ND60 & $53.95(0.4)$ & $0.47(2.4)$ & $15.14(0.6)$ & bdl & $8.39(0.8)$ & $0.17(8.3)$ \\
\hline ND69 & $50.036(0.8)$ & $1.17(1.0)$ & $15.79(1.2)$ & 0.05 (15.7) & $9.26(2.3)$ & 0.19 (11.6) \\
\hline ND61 & $54.63(1.1)$ & $0.43(3.2)$ & $14.45(0.7)$ & bdl & $8.16(1.7)$ & 0.17 (15.9) \\
\hline ND70 & $49.11(0.3)$ & $0.84(2.4)$ & $16.10(0.3)$ & $0.06(8.6)$ & $8.06(0.8)$ & $0.16(14.1)$ \\
\hline 24.1 & $50.33(1.1)$ & $1.42(1.6)$ & $13.46(0.7)$ & bdl & $12.06(1.0)$ & $0.24(17.0)$ \\
\hline \multicolumn{7}{|l|}{$\underline{\text { Olivine }}$} \\
\hline San Carlos & $40.29(1.1)$ & bdl & bdl & bdl & $10.38(0.9)$ & $0.16(8.5)$ \\
\hline $\mathrm{Pk} O \mathrm{Ol}$ & $41.42(0.6)$ & bdl & bdl & bdl & $4.87(1.23)$ & $0.16(8.5)$ \\
\hline \multicolumn{7}{|l|}{ Pyroxene } \\
\hline Tan opx & $57.53(0.4)$ & $0.04(22.3)$ & $0.11(11.7)$ & bdl & $6.34(1.2)$ & $0.26(7.8)$ \\
\hline PMR-53 срх & $54.28(0.7)$ & $0.37(4.3)$ & $2.85(0.5)$ & $0.16(12.5)$ & 7.25 (1.2) & $0.19(19.2)$ \\
\hline KBH cpx & $50.55(0.4)$ & $0.41(2.2)$ & $6.77(0.4)$ & $1.07(3.8)$ & $2.86(1.8)$ & $0.11(31.5)$ \\
\hline Cr diop & $54.046(0.5)$ & $0.07(13.1)$ & $0.21(5.8)$ & $0.66(2.3)$ & $1.06(2.6)$ & $0.07(20.2)$ \\
\hline KBH opx & $54.03(0.6)$ & $0.11(9.8)$ & $4.93(1.3)$ & $0.53(3.7)$ & $6.18(1.8)$ & 0.15 (13.5) \\
\hline
\end{tabular}

RSD are in parenthesis, based on $n=7$.

bdl $=$ below detection limit.

$\mathrm{FeO}^{\mathrm{t}}=$ total $\mathrm{Fe}$ 


\begin{tabular}{llllll}
\hline $\mathrm{MgO}$ & $\mathrm{CaO}$ & $\mathrm{Na}_{2} \mathrm{O}$ & $\mathrm{K} 2 \mathrm{O}$ & $\mathrm{NiO}$ & \multicolumn{2}{l}{ Total } \\
\hline \hline & & & & & \\
& & & & & \\
$5.24(1.1)$ & $9.66(0.8)$ & $2.95(2.8)$ & $0.12(15.2)$ & $\mathrm{bdl}$ & 98.23 \\
$6.38(0.8)$ & $11.02(0.5)$ & $1.50(5.0)$ & $0.49(5.1)$ & $\mathrm{bdl}$ & 97.51 \\
$7.03(1.2)$ & $11.45(1.8)$ & $2.85(2.9)$ & $0.32(4.4)$ & $\mathrm{bdl}$ & 98.10 \\
$6.65(0.9)$ & $11.18(0.7)$ & $1.61(6.4)$ & $0.49(5.1)$ & $\mathrm{bdl}$ & 97.77 \\
$8.63(0.8)$ & $12.80(0.9)$ & $2.19(4.6)$ & $0.18(9.8)$ & $\mathrm{bdl}$ & 98.13 \\
$6.94(0.9)$ & $11.05(0.8)$ & $2.36(19.0)$ & $0.07(19.6)$ & $\mathrm{bdl}$ & 97.93 \\
& & & & & \\
$49.37(0.3)$ & $0.08(12.9)$ & $\mathrm{bdl}$ & $\mathrm{bdl}$ & $0.36(5.7)$ & 100.64 \\
$53.64(0.1)$ & $\mathrm{bdl}$ & $\mathrm{bdl}$ & $\mathrm{bdl}$ & $0.33(6.4)$ & 100.43 \\
& & & & & 100.16 \\
$35.74(0.2)$ & $0.14(3.4)$ & $0.07(0.0)$ & $\mathrm{bdl}$ & $\mathrm{bdl}$ & 99.68 \\
$18.65(0.6)$ & $13.86(0.4)$ & $1.97(5.0)$ & $0.042(29.6)$ & $0.08(14.5)$ & 99.11 \\
$15.70(0.2)$ & $20.00(0.3)$ & $1.62(3.4)$ & $\mathrm{bdl}$ & $0.07(8.6)$ & 99.59 \\
$17.94(0.5)$ & $25.22(0.1)$ & $0.36(11.3)$ & $\mathrm{bdl}$ & $\mathrm{bdl}$ & 100.23 \\
$33.18(0.4)$ & $0.87(2.5)$ & $0.14(18.0)$ & $\mathrm{bdl}$ & $0.11(6.4)$ & \\
\hline
\end{tabular}


Table 2: Results of water analyses

\begin{tabular}{|c|c|c|c|c|}
\hline Sample name & $\begin{array}{c}\text { SHRIMP SI } \\
{ }^{16} \mathrm{OH} /{ }^{16} \mathrm{O}(\mathrm{n}=3)^{*}\end{array}$ & $\begin{array}{l}1 \sigma \text { standard } \\
\text { deviation }\end{array}$ & $\begin{array}{l}\text { reproducibility } \\
(\%)\end{array}$ & $\begin{array}{l}\mathrm{H}_{2} \mathrm{O}(\mathrm{ppm}) \\
\text { SHRIMP SI } \\
\text { calibrated } t\end{array}$ \\
\hline \multicolumn{5}{|l|}{ Glasses } \\
\hline 36.4 & $1.51 \mathrm{E}-03$ & $5.52 \mathrm{E}-06$ & 0.37 & $7.73 E+03$ \\
\hline 24.1 & 7.69E-04 & $1.18 \mathrm{E}-06$ & 0.15 & $3.87 E+03$ \\
\hline ND60 & $2.74 \mathrm{E}-03$ & $9.21 \mathrm{E}-06$ & 0.34 & $1.42 \mathrm{E}+04$ \\
\hline ND61 & $2.53 \mathrm{E}-03$ & $3.56 \mathrm{E}-05$ & 1.41 & $1.31 \mathrm{E}+04$ \\
\hline ND69 & $2.47 \mathrm{E}-03$ & 7.91E-07 & 0.03 & $1.27 \mathrm{E}+04$ \\
\hline ND70 & $1.99 \mathrm{E}-03$ & $2.08 \mathrm{E}-06$ & 0.10 & $1.02 \mathrm{E}+04$ \\
\hline \multicolumn{5}{|l|}{ Olivine } \\
\hline San Carlos & 4.35E-05 & $1.94 \mathrm{E}-06$ & 4.46 & 81 \\
\hline Pk-olivine & $8.10 \mathrm{E}-05$ & 8.01E-07 & 0.99 & 277 \\
\hline \multicolumn{5}{|l|}{ Pyroxene } \\
\hline KBH-1 opx & $7.40 \mathrm{E}-05$ & $1.20 \mathrm{E}-06$ & 1.62 & 240 \\
\hline Tan opx & 3.67E-05 & $1.98 \mathrm{E}-07$ & 0.54 & 45 \\
\hline Rus Cr-diop & $5.53 \mathrm{E}-05$ & $2.16 \mathrm{E}-06$ & 3.91 & 142 \\
\hline $\mathrm{KBH} c p x$ & $1.01 \mathrm{E}-04$ & $5.26 \mathrm{E}-06$ & 5.21 & 381 \\
\hline PMR-53 cpx & 8.01E-05 & $8.00 \mathrm{E}-07$ & 1.00 & 272 \\
\hline
\end{tabular}

*Analytical error per SHRIMP SI and Cameca analysis is typically less than $2 \%$.

+ Calibration determined by single weighted line fit to all standard data (see text).

\# $\mathrm{H}_{2} \mathrm{O}(\mathrm{ppm})$ contents of samples determined by the calibration curves of Hauri et al. 200 $\S 1$ standard deviation error on samples analysed in this study $(n=>6)$. All other errors fo References for $\mathrm{H} 2 \mathrm{O}$ determination by (F) or (M) are as follows: (1) this study (2) Bell et al 


\begin{tabular}{|c|c|c|c|c|c|}
\hline $\begin{array}{l}\text { Cameca 6F } \\
{ }^{16} \mathrm{OH} /{ }^{30} \mathrm{Si}(\mathrm{n}=4)^{*}\end{array}$ & $\begin{array}{l}1 \sigma \text { standard } \\
\text { deviation }\end{array}$ & $\begin{array}{l}\text { reproducibility } \\
\text { (\%) }\end{array}$ & $\begin{array}{l}\mathrm{H}_{2} \mathrm{O}(\mathrm{ppm}) \\
\text { Cameca } \\
\text { calibrated\# }\end{array}$ & $\begin{array}{l}\mathrm{H}_{2} \mathrm{O}(\mathrm{ppm}) \mathrm{FTIR} \\
(\mathrm{F}) \text { or } \\
\text { Manometry (M) }\end{array}$ & $\begin{array}{l}1 \sigma \text { standard } \\
\text { deviation§ }\end{array}$ \\
\hline 1.89 & $1.00 \mathrm{E}-01$ & 5.29 & $8.61 \mathrm{E}+03$ & $7.40 \mathrm{E}+03$ & $5.32 \mathrm{E}+02$ \\
\hline 0.85 & $6.92 \mathrm{E}-03$ & 0.81 & $3.90 \mathrm{E}+03$ & $3.10 \mathrm{E}+03$ & $3.36 \mathrm{E}+02$ \\
\hline 3.41 & $6.16 \mathrm{E}-02$ & 1.81 & $1.56 \mathrm{E}+04$ & $1.61 \mathrm{E}+04$ & $4.66 \mathrm{E}+02$ \\
\hline 3.06 & $7.43 \mathrm{E}-03$ & 0.24 & $1.40 \mathrm{E}+04$ & $1.39 \mathrm{E}+04$ & $3.27 \mathrm{E}+02$ \\
\hline 3.14 & $5.14 \mathrm{E}-02$ & 1.64 & $1.43 E+04$ & $1.34 \mathrm{E}+04$ & $1.03 \mathrm{E}+02$ \\
\hline 2.47 & $4.72 \mathrm{E}-02$ & 1.91 & $1.13 \mathrm{E}+04$ & $9.98 \mathrm{E}+03$ & $4.65 \mathrm{E}+01$ \\
\hline $4.08 \mathrm{E}-03$ & $1.45 \mathrm{E}-03$ & 35.54 & 15 & $10(F)$ & 2 \\
\hline 7.37E-02 & 7.67E-04 & 1.04 & 338 & $337(F)$ & 41 \\
\hline 5.59E-02 & $9.15 \mathrm{E}-04$ & 1.64 & 216 & $217(\mathrm{M})$ & 14 \\
\hline $1.03 \mathrm{E}-02$ & 3.31E-04 & 3.21 & 40 & $33(F)$ & 4 \\
\hline $2.59 \mathrm{E}-02$ & 4.64E-04 & 1.79 & 100 & $125(F)$ & 14 \\
\hline $8.49 \mathrm{E}-02$ & $2.26 \mathrm{E}-03$ & 2.66 & 498 & $530(\mathrm{M})$ & \\
\hline $5.60 \mathrm{E}-02$ & $2.89 \mathrm{E}-04$ & 0.52 & 328 & 268(M) & 7.5 \\
\hline
\end{tabular}

12 and Koga et al. 2003. Errors associated with this calibration is approximately $10 \%$ for glass and $20 \%$ for $r$ und in references.

. 1995 (3) Bell and Rossman 1992. 


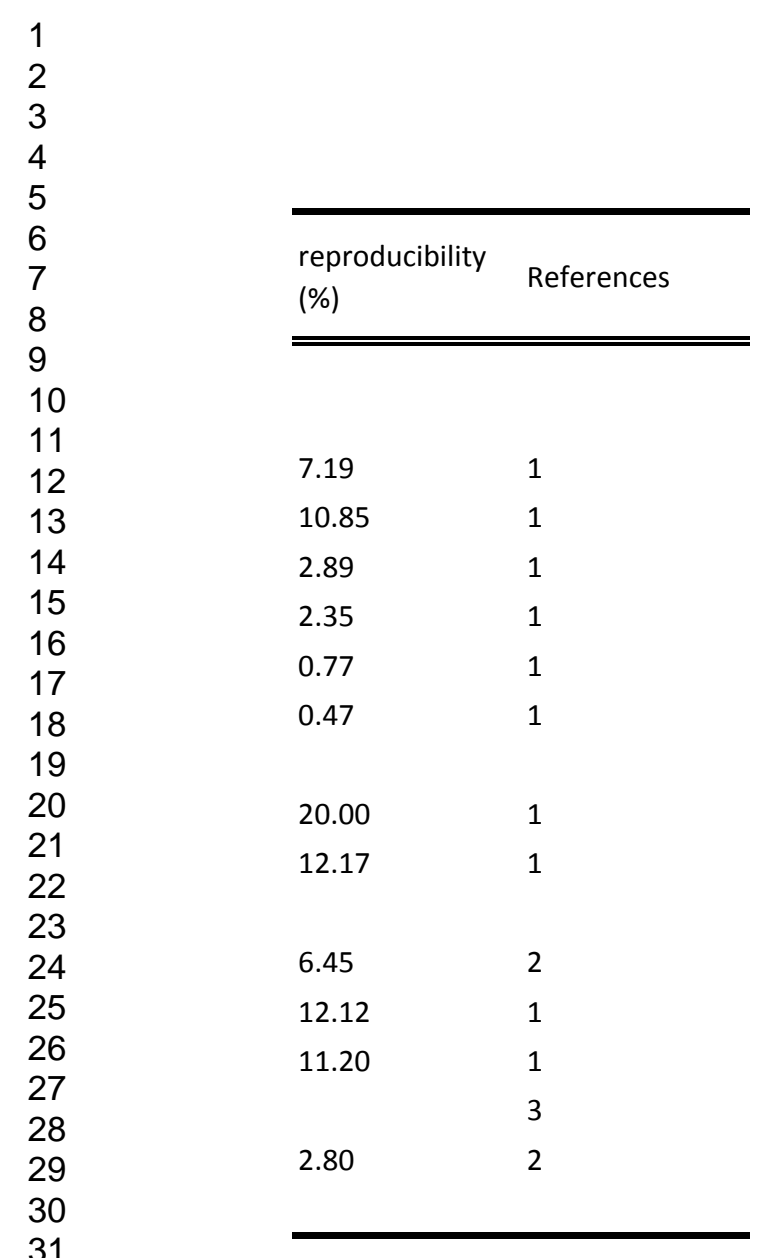

31

33

34

35

36

37

38

39

40

41

42

43

44

45

46

47

48

49

50

51

52

53

54

55

56

57

58

59

60

ninerals 
Table 3: Compilation of water contents of basaltic glasses determined by FTIR

\begin{tabular}{lrllrr}
\hline Sample & thickness $(\mu)$ & \pm & density & $3550 \pm$ \\
& & & \\
& & & \\
\hline \hline ND 60 & 82 & 4 & 2650 & 1.23 & 0.03 \\
ND 61 & 92 & 4 & 2650 & 1.19 & 0.01 \\
Nd 69 & 82 & 4 & 2650 & 1.03 & 0.03 \\
ND 70 & 142 & 3 & 2650 & 1.32 & 0.03 \\
36.4 & 142 & 3 & 2650 & 0.972 & 0.004 \\
24.1 & 142 & 3 & 2650 & 0.402 & 0.007 \\
& & & & & \\
\hline
\end{tabular}

*Water contents calculated with a density of $2650 \pm 50$; e(3570) of $63.32 \pm 0.42$ and e(1630) of $42.34 \pm 2.77$ for Fe-bearing anc 
1

2

3

4

5

6

7

8

9

10

11

12

13

14

15

16

17

18

19

20

21

22

23

24

25

26

27

28

29

30

31

32

33

34

35

36

37

38

39

40

41

42

43

44

45

46

47

48

49

50

51

52

53

54

55

56

57

58

59

60

\begin{tabular}{lcccc}
\hline & $1630 \pm$ & \multicolumn{3}{c}{$* \mathrm{H}_{2} \mathrm{O}(\mathrm{ppm}) \quad$ } \\
\hline \hline & & & & \\
& 0.154 & 0.004 & $1.61 \mathrm{E}+04$ & $5.32 \mathrm{E}+02$ \\
& 0.145 & 0.003 & $1.39 \mathrm{E}+04$ & $3.36 \mathrm{E}+02$ \\
& 0.076 & 0.002 & $1.34 \mathrm{E}+04$ & $4.66 \mathrm{E}+02$ \\
& 0.055 & 0.003 & $9.98 \mathrm{E}+03$ & $3.27 \mathrm{E}+02$ \\
& 0.03 & 0.0005 & $7.40 \mathrm{E}+03$ & $1.03 \mathrm{E}+02$ \\
bdl & & & $3.10 \mathrm{E}+03$ & $4.65 \mathrm{E}+01$ \\
& & & & \\
\hline
\end{tabular}

lesites from Mandaveille et al. 2002 
Table 4. FTIR data of NAMs used in this study

\begin{tabular}{|c|c|c|c|c|c|c|c|}
\hline \multirow[t]{2}{*}{ Sample } & \multirow[t]{2}{*}{ Locality } & \multicolumn{3}{|c|}{ IR integrated absorbance $\left(\mathrm{cm}^{-2}\right)$} & \multirow{2}{*}{$\begin{array}{l}A(\text { total) } \\
\mathrm{cm}^{-2}\end{array}$} & \multirow{2}{*}{$\begin{array}{c}\mathrm{H}_{2} \mathrm{O}, \text { Bell } \\
\text { ppm wt }\end{array}$} & \multirow{2}{*}{$\begin{array}{r}\mathrm{H}_{2} \mathrm{O}, \mathrm{Kc} \\
\mathrm{ppm} \\
\end{array}$} \\
\hline & & a & $\mathrm{b}$ & g & & & \\
\hline$\overline{C r \text {-diop }}$ & Russia & $391(20)$ & $304(15)$ & $193(10)$ & 888 & $125(14)$ & \\
\hline Tan opx & Tanzania & $138(7)$ & 75 (4) & 282 (14) & 495 & $33(4)$ & \\
\hline Pk-olivine & Pakistan & $295(15)$ & $70(4)$ & $225(11)$ & 591 & $111(14)$ & 337 \\
\hline SC olivine & San Carlos & $3(1)$ & $9(1)$ & $40(4)$ & 52 & $10(2)$ & \\
\hline
\end{tabular}

Notes: integration range are 3750-3000 cm-1 for cpx, 3750-2800 cm-1 for opx and 3750-3300 for ol, "Bell" refers to calibrations by Bell et al. (1995 Bell et al. (2003) for pyroxenes and olivines respectively. "Kovács" referes to Kovács et al. (2010) for olivine. 


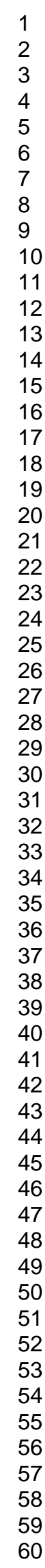

Jvács

$\underline{\underline{w t}}$

(41)

13

14 ;) and

16

17

18

19

20

21

23

24

25

26

27
28

29

30

31

34

35

36

37

38

39

40

41

42

44

45

46

47

48

49

50

52

53

54

55

57

58

59

60 